\title{
RONILZA MATOS
}

Uso da secagem prolongada como uma alternativa de aprimoramento do método de fluorescência a laser na avaliação da atividade de lesões de cárie em dentes decíduos: estudo in vivo

São Paulo

2012 


\title{
RONILZA MATOS
}

Uso da secagem prolongada como uma alternativa de aprimoramento do método de fluorescência a laser na avaliação da atividade de lesões de cárie em dentes decíduos: estudo in vivo

\author{
Versão Original
}

Tese de Doutorado apresentada no Curso de Pós-Graduação em Ciências Odontológicas junto à Faculdade de Odontologia da Universidade de São Paulo para obtenção do título de Doutor.

Área de Concentração: Odontopediatria

Orientadora: Profa. Dra Mariana Minatel Braga

São Paulo 
Matos R. Uso da secagem prolongada como uma alternativa de aprimoramento do método de fluorescência a laser na avaliação da atividade de lesões de cárie em dentes decíduos: estudo in vivo. Tese apresentada à Faculdade de Odontologia da Universidade de São Paulo para obtenção do título de Doutor em Ciências Odontológicas.

Aprovado em: / /2013

\section{Banca Examinadora}

Prof(a).Dr.(a). Instituição:

Julgamento: Assinatura:

Prof.(a). Dr.(a). Instituição:

Julgamento: Assinatura:

Prof.(a). Dr.(a). Instituição:

Julgamento: Assinatura:

Prof.(a). Dr.(a). Instituição:

Julgamento: Assinatura:

Prof.(a). Dr.(a). Instituição:

Julgamento: Assinatura: 
Dedico este trabalho aos meus pais Raimundo e Nilcia e as minhas irmãs Ronilce, Regiane e Izaura, por serem meus exemplos e a minha sustentação nesta caminhada. Ao meu querido tio amigo José Pereira dos Santos (in memorian) que com muita luta, amor e carinho, foi o grande patriarca da família Matos. Amo vocês! 


\section{AGRADECIMENTOS}

Agradeço aos meus pais pelo amor incondicional e dedicação na criação das quatro filhas. Aprendi com vocês que devemos dar o nosso melhor sempre. Assim, seremos serenos e teremos a sensação que fizemos tudo o que poderíamos fazer em todas as esferas das nossas vidas.

Ao meu pai Raimundo (Zebrinha), uma fortaleza! Agradeço todos os dias por ter escolhido você para ser meu pai. Sempre pronto a consolar e ajudar o próximo, sem medir esforços. Somos uma família feliz e encaramos a vida de uma maneira positiva, graças ao senhor. Te amo!

À minha mãe Nilcia, mãezinha linda. Obrigada por todo amor, por ser uma leoa em nossa criação e por semeado o amor no meu coração.

À minha irmã Regiane, leãozinho!!! Queria te agradecer por não ter desistido. A sua recuperação/superação é uma lição para todos. Não sou mãe ainda, mas sinto um amor incondicional por você. Estamos e estaremos sempre juntas.

À minha irmã Izaurinha, por toda a sabedoria e zelo. Obrigada por todo o cuidado e atenção. Por ser um ombro amigo quando mais precisei. Por saber, com tão pouca idade, aceitar e superar as diversidades que a vida impõe. " $\mathrm{O}$ céu de repente anuviou/ $\mathrm{E}$ o vento agitou as ondas do mar/ $\mathrm{E}$ o que o temporal levou/ Foi tudo o que deu para ajuntar/ Só Deus sabe o quanto se labutou/ Custou, mas depois veio a bonança/ E agora é hora de agradecer/ Pois quando tudo se perdeu/ E a sorte desapareceu/ Abaixo de Deus só ficou você..." (Claudinho Guimarães). Agradeço à Deus por você existir e estar presente nas nossas vidas. Te amo incondicionalmente. 
À minha irmã Ronilce!! Irmã, você é minha alma gêmea e o melhor é que nós duas concordamos com isso. Estamos e estaremos sempre juntas. Te amo muito!!! "Quem me dará um ombro amigo/ Quando eu precisar?/ E se eu cair, se eu vacilar/ Quem vai me levantar?/ Sou eu, quem vai ouvir você/ Quando o mundo não puder te entender/ Foi Deus, quem te escolheu pra ser/ O melhor amigo que eu pudesse ter." ( Dalvimar Gallo)

Ao meu querido Tio Zé, obrigada por tudo. O senhor me nomeou "Tuca" e assim foi. O patriarca da família Matos, nunca mediu esforços para estar conosco e nos proporcionar momentos únicos nas belas tardes de domingo durante a minha infância na sua casa, na Páscoa, Natal, aniversários das pessoas da nossa família, nas férias na Fazenda Capoeira (Euclides da Cunha - Bahia). Sempre nos recebendo com um sorriso no rosto. Sinto muito a tua falta, mas sei que você está em um lugar muito especial e sempre estará presente nas nossas memórias e corações.

À família Matos. Meus tios e tias amados e amáveis. Especialmente aos meus primos Samir, Jô, Luciano, Mazinho, Nida, Nininha, Jeane, João, Genira, Alice, Vanessa, Luana, Mila, Ana Julia, Márcia, Jorge e Erica (in memorian). Vocês são mais que primos. Somos uma família de verdade, unida em todos os momentos. Agradeço a Deus por estarmos juntos nesta caminhada. É muito bom saber que posso contar com vocês.

Vovô Jorge e Vovó Judith. Tenho muito orgulho de vocês. Obrigada pela ótima convivência, pelo amor, pelo carinho, pela alegria na minha chegada e por preservar o meu refúgio: a Fazenda Capoeira! 
À minha orientadora Mariana Minatel Braga Fraga, simplesmente Mari. Obrigada por todos as oportunidades oferecidas e por defender os interesses das suas orientadas com toda forca e garra. Chefinha, nos conhecemos a 10 anos e nossa amizade é muito importante para mim. Tenho muito orgulho de você e de fazer parte da sua vida. Obrigada por toda sabedoria, paciência e dedicação durante esta jornada. Gostaria de destacar como foi importante a sua demonstração de carinho e afeto no momento mais difícil da minha vida. Você não poupou esforços para me deixar à vontade e para dedicar o meu tempo à minha família quando mais precisamos.

Ao meu eterno chefe, amigo e companheiro: Fausto Medeiros Mendes. Agradeço a Deus todos os dias por você estar no meu caminho. Você me descobriu e minha vida mudou totalmente. Sou eternamente grata por todas as oportunidades, pelas conquistas e momentos de alegria que você me proporcionou. Sua força de vontade e energia são as mais admiráveis.

À Professora Ana Carolina Magalhães, pela honra de tê-la em minha banca. Pelas importantes considerações realizadas na minha qualificação: obrigada.

Ao Prof. Marcelo Bonecker, por proporcionar um ambiente de trabalho produtivo e harmônico.

À querida Profa. Dani P. Raggio, que foi a minha primeira professora de Odontopediatria e a responsável por plantar essa semente no meu coração. Você é muito especial, te adoro!

À Profa. Ana Lídia, por seu exemplo de vida, que nos ensina diariamente como podemos tocar as nossas vidas com dedicação e humildade.

À Profa. Ana Estela Haddad, pela cordial convivência e seriedade. 
Ao Prof. Imparato por todas as oportunidades oferecidas. Imparato, se hoje estou na FOUSP foi porque você me abriu as portas. A minha admiração por você é de longa data e aumenta a cada dia. Sou imensamente grata por fazer parte da sua equipe e por ter sido convidada para ser Professora da disciplina de Clinica Odontológica Integrada Infantil do Centro Universitário Hermínio Ometto (UNIARARAS). Sem duvidas, esse foi um divisor de águas na minha vida.

Ao meu orientador do mestrado, Prof. Danilo Antonio Duarte, pelo apoio cientifico, pela paciência e dedicação nas minhas dúvidas, pelas manifestações explícitas de alegria nas minhas conquistas! Você é um exemplo a ser seguido! À Profa. Márcia T. Wanderley, pelo carinho e atenção.

À Profa. Maria Salete Nahás P. Correa, sou muito abençoada em poder tê-la conhecido. Você é um ser muito iluminado e querido.

À Profa. Patrícia Freitas, você não mediu esforços para realização da nossa pesquisa.

À minha "prima" Adriana L. Ortega. Sua força de vontade e dedicação são admiráveis. Obrigada por alegrar os meus dias. Foi um prazer trabalhar com você na clinica de adolescentes.

À Gabriela Bonini, por toda a amizade e confiança no meu trabalho. Gostaria de agradecer todo o carinho demonstrado quando eu mais precisei dos amigos. Agradeço a Deus por ter colocado você no meu caminho. Você é uma guerreira digna de toda a felicidade do mundo. Você e sua família estarão sempre presentes nas orações da família Matos. Te amo! 
À minha querida Anna Carolina, Babou. Você é sensacional: ótima amiga, filha, esposa, irmã, profissional. Mulher nota mil. Obrigada do fundo do meu coração por toda a amizade, companheirismo e pelas inúmeras oportunidades. Amo conviver com você, me sinto privilegiada por ser sua amiga. Quando mais precisei de um amigo, você não mediu esforços para me consolar. Serei eternamente grata por tudo que você e sua família fizeram no momento mais difícil da minha vida. Tenha certeza que vocês sempre estarão presentes nas nossas orações. Te amo!

Tati, minha amiga, companheira e confidente. Obrigada por tudo! Palavras não são suficientes para expressar o que você representa na minha vida. Você é uma pessoa abençoada. Nossos caminhos se cruzaram por uma causa nobre! Nada é por acaso! Sou muito feliz por fazer parte da sua vida. A sua participação na realização deste trabalho é enorme. Obrigada por todo empenho e amizade quando mais precisei. Te amo!

À minha parceira e amiga Alessandra Reyes. Serei eternamente grata a você. Você é uma pessoa impar. Amiga fiel, extremamente carinhosa e sempre disposta a ajudar. Desejo que você seja muito feliz! Você, juntamente com a Tati, foram indispensáveis para a realização deste trabalho. Você me deu um dos meus maiores presentes nesta caminhada: a oportunidade de conhecer o Élio Shinohara e saber que a Regiane esta em ótimas mãos.

Ao Prof. Élio Shinohara e sua equipe por todo o carinho e atenção no tratamento da minha irmã Regiane. Élio, você foi um presente de Deus nas nossas vidas. A sua indiscutível capacidade, segurança e carinho durante a nossa jornada, foi de extremamente importante para aliviar os corações dos membros da família Matos. Serei eternamente grata. 
À minha amada Nadia Salem, Nadinha. Como você é especial e se tornou, em tão pouco tempo, indispensável na minha vida. A nossa amizade é algo que me faz tão bem. Somos parceiras em tudo. Obrigada por fazer a minha vida melhor a cada dia. Aprendo muito com você. Nossas sessões de terapia durante o trajeto São Paulo - Araras alegram o meu dia e a minha vida. Você é ser lindo. Uma ótima amiga, profissional, filha e irmã. Te admiro muito e rezo para que a nossa amizade e convivência seja linda e duradoura. Te amo muito, Habibiti!

À minha querida Dani Bittar. Te amo muito! Você fez toda a diferença naquele departamento. Sinto-me privilegiada por ser sua amiga e, também, por ter sido escolhida para ser madrinha, juntamente com a Nadinha, do seu casamento com o Pedro. Que a nossa amizade perdure sempre!!!

Às minhas amadas:

Thaís Gimenez. Uma pessoa fiel aos seus princípios e amizades. Sempre disposta a ser um ombro amigo. Te amo muito.

Vanessinha. Quantas risadas! Nós soubemos aproveitar muito bem o nosso tempo juntas. Te amo!

Chaia linda! Um ser humano lindo por dentro e por fora. Estou muito feliz por suas conquistas. Você merece toda a felicidade e sucesso.

Levy! Obrigada pelo carinho e a ótima companhia em todos os momentos que vivenciamos.

Karlinha, Dani Hesse, Camilinha, Tati Lenzi, Juan, Tamara, Chris Murakami, Jana, Ana Flavia, Jenny, Juliana Kimura, Juliana Mattos, Isabela Floriano, Patrícia, Gustavo, Caleb e Helena pela adorável convivência. 
Lucila (Nina): Você mora no meu coração. Obrigada pelo apoio nos diversos momentos da minha vida.

Cássio. Em um primeiro momento, você foi um professor e quando eu menos esperava nos tornamos amigos. Você é muito especial e mora no meu coração. Obrigada por tudo.

Aos amigos Fábio, Roberto, Johnny, Marina, Giovanna, Simone, Ju Meloni, Paty Flor, Luana Torelli, Brunno D’Viola, Rodrigo Ueno e Edna Miranda por toda a amizade.

À minha amiga de infância Dani Fantini, por todo a amizade compartilhada.

À minha amada amiga Maithê, por tudo o que você representa na minha vida. Te admiro muito. Você é uma amiga muito especial, minha irmãzinha do coração. Te amo muito!!

À família Amaral, minha família baiana. Obrigada pela ótima convivência e acolhida. Serei eternamente grata!! Vocês moram no meu coração.

Às queridas e competentes Suzana Portugal e Rayen Drugowick. Gostaria de agradecer pela ótima convivência e amizade desprendida durante este ano. É um prazer trabalhar com vocês. Obrigada por tudo!

À Sofia Uemura por toda a dedicação e competência como coordenadora do curso de Odontologia da UNIARARAS.

Aos meus alunos de graduação e pós-graduação pela ótima convivência e aprendizado na arte de ser professor.

Aos funcionários do departamento: Julio, Fátima, Antonio, Ane e Marize, pela atenção, carinho e cuidado com os alunos deste departamento. Muito Obrigada. 
Às funcionárias do Lelo: Gê, Elaine e Lili proprocionam um ambiente de trabalho organizado e harmônico, vocês foram verdadeiros anjos. Muito Obrigada.

Às bibliotecárias do SDO/FOUSP pela elaboração da ficha catalográfica e revisão em tempo recorde; e à Donata, secretária da pós graduação por sempre nos receber com um sorriso e por desempenhar tão bem o seu papel. Muito Obrigada.

Aos pacientes da pesquisa pela dedicação e empenho. Obrigada. 
"Nunca se entregue, nasça sempre com as manhãs.

Deixe a luz do sol brilhar no céu do seu olhar.

Fé na vida, fé no homem, fé no que virá.

Não podemos tudo, nós podemos mais.

Vamos lá fazer o que será.

Luiz Gonzaga do Nascimento Junior (Gonzaguinha) 


\section{RESUMO}

Matos R.Uso da secagem prolongada como uma alternativa de aprimoramento do método de fluorescência a laser na avaliação da atividade de lesões de cárie em dentes decíduos: estudo in vivo [tese]. São Paulo: Universidade de São Paulo, Faculdade de Odontologia; 2012. Versão Original.

O presente trabalho objetivou testar o uso da secagem prolongada (30s) na tentativa de melhorar a habilidade do método de fluorescência a laser em avaliar a atividade de lesões de cárie oclusais em dentes decíduos. Noventa e três crianças, com idade entre 4 e 14 anos, concluíram todas as fases deste estudo. Um examinador, previamente treinado, realizou as medições, após secagem prévia por 3 segundos (controle) e 30 segundos, com o aparelho de fluorescência a laser (Ddpen) nas superfícies oclusais dos molares decíduos selecionados $(n=515)$. Para a validação concorrente, os dentes previamente selecionados foram classificados por dois examinadores quanto à presença e atividade das lesões de cárie através do critério de inspeção visual ICDAS e a avaliação da atividade das lesões foi realizada através da ponderação mental das características clinicas da lesões. Para a validação preditiva, após 1 ano do exame inicial, 19 crianças foram reexaminados pelos métodos descritos acima. Com o intuito de verificar a habilidade do método em diferenciar lesões ativas e inativas, foram consideradas as medições após $3 \mathrm{~s}$ e $30 \mathrm{~s}$ de secagem, além da diferença entre essas medidas (DIF 30s-3s). Para isso, foram utilizadas análises de regressão linear multinível. Para a validação preditiva, modelos de regressão logística foram usados e o risco relativo com intervalo de confiança de $95 \%$ foi calculado. Houve discreta diferença entre os dois tempos de secagem (3s e 30s). Para as lesões clinicamente em esmalte, não houve diferença na magnitude das leituras do DDpen, independentemente do tempo de secagem utilizado. Entretanto, quando foi considerado somente lesões não cavitadas, observaram-se, em média, maiores leituras para as lesões de cárie inativas do que para as ativas, efeito que desapareceu quando a análise foi ajustada pela pigmentação das lesões não cavitadas. A DIF 30s-3s não 
contribuiu na diferenciação de lesões inativas e ativas, nem considerando lesões clinicamente em esmalte, nem apenas as lesões não cavitadas. As lesões cavitadas ativas tiveram maior leitura de fluorescência a laser que as lesões inativas. $\mathrm{Na}$ validação preditiva, as medidas de fluorescência a laser também não foram associadas à progressão das lesões, nem à alteração do status de atividade. Isso foi válido para ambos os tempos de secagem e para a DIF 30s-3s. Conclui-se que a fluorescência a laser é capaz de diferenciar, quanto à atividade, apenas lesões de cárie cavitadas, independente do tempo de secagem utilizado e que a medida da diferença entre as leituras obtidas após secagem de 3s e 30s não auxilia na classificação do status de atividade das lesões de cárie não cavitadas.

Palavras-chave: Testes de atividade de cárie. Fluorescência a laser. Dentes decíduos. 


\begin{abstract}
Matos R. Use of prolonged drying as an alternative to improve the laser fluorescence method to assess activity caries lesions in primary teeth: an in vivo study [thesis]. São Paulo: Universidade de São Paulo, Faculdade de Odontologia; 2012. Versão Original.
\end{abstract}

The aim of the current study was to test the use of an extended drying period (30s), in order to improve the laser fluorescence ability for assessing active and inactive occlusal caries lesions in primary teeth. Ninety-three children, aged 414 yrs-old, were involved in all steps of the study. One examiner, previously trained, performed measurements with laser fluorescence (Ddpen), after 3s and $30 \mathrm{~s}$ of previous air-drying, on the occlusal surfaces of selected primary molars $(n=515)$. For the concurrent validation, all previously selected teeth were classified using the ICDAS and the lesion activity assessment was performed through mental weighing of clinical characteristics. For the predictive validation, 19 children were evaluated again following the same criteria mentioned above. Measurements collected after 3 and $30 \mathrm{~s}$ of air-drying, and also the difference between them (DIF 30s-3s) were calculated, aiming to verify the ability of the method to differentiate active and inactive lesions. For this, multilevel linear regression analyses were performed. For the predictive validation, logistic regression models were considered and the relative risk with a confidence interval of $95 \%$ was also calculated. A slight difference between values was found, for both drying periods (3s and 30s). Concerning the lesions that were clinically classified in enamel, no significant statistical difference was observed on laser fluorescence readings, independently of air-drying time. However, when considering only non-cavitaded lesions, higher mean readings were observed for the inactive lesions than for the active ones. However, this effect disappeared when adjusting the analysis for the stained non-cavitaded lesions. The DIF 30s-3s did not contribute to distinguishing active and inactive lesions. Active cavitated lesions presented higher DDpen readings than inactive cavitated lesions. In the predictive validation, the measurements of laser 
fluorescence were not also associated to the greatest risk of progression or changes in the status of the activity. It was concluded that the Ddpen is suitable to differentiate cavitated active and inactive lesions independently of the drying period, and that the difference measurement between the obtained readings after 3 s and 30 s of air-drying does not help in caries activity assessment of noncavitated caries lesions.

Keywords: Caries activity tests. Laser fluorescence. Primary teeth. 
1 INTRODUÇÃO

2 REVISÃO DA LITERATURA

2.1 DIAGNÓSTICO DE ATIVIDADE DA LESÃO DE CÁRIE.................................... 20

2.2 O USO DA FLUORESCÊNCIA A LASER NA CARIOLOGIA ............................ 23

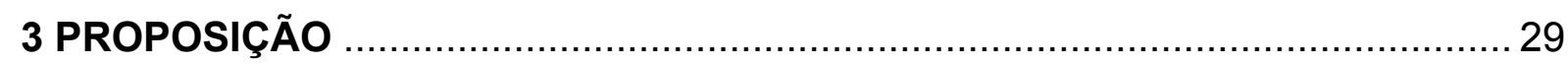

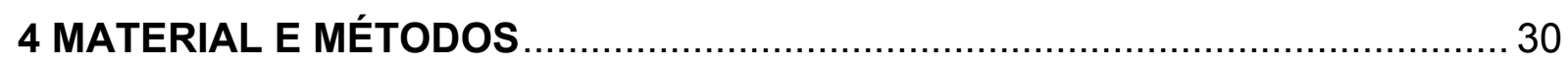

4.1 SELEÇÃO DOS SUJEITOS DO ESTUDO ………..................................... 30

4.2 EXAME COM MÉTODO DE FLUORESCÊNCIA INDUZIDA POR LASER

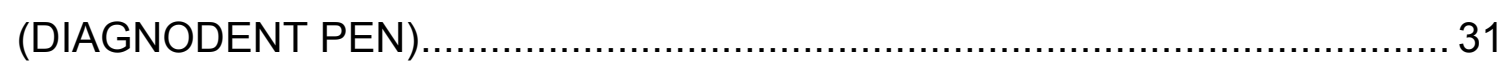

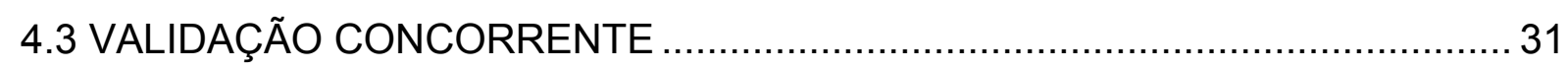

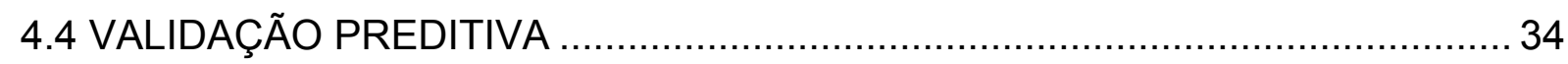

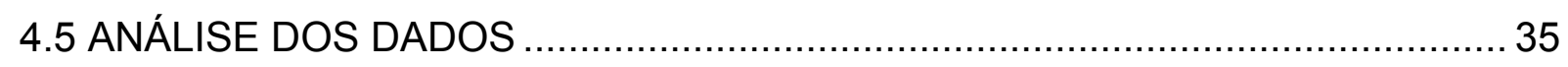

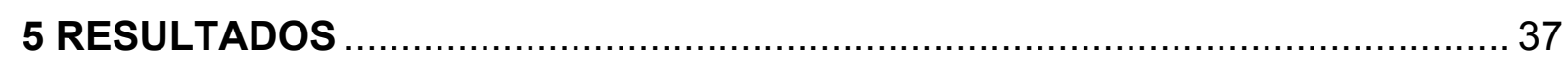

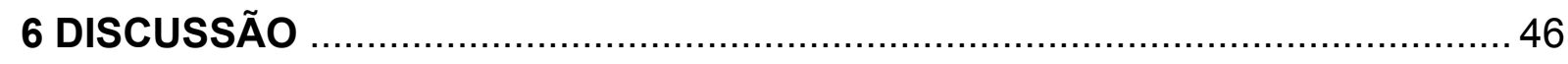

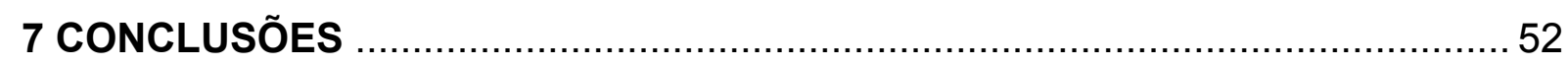

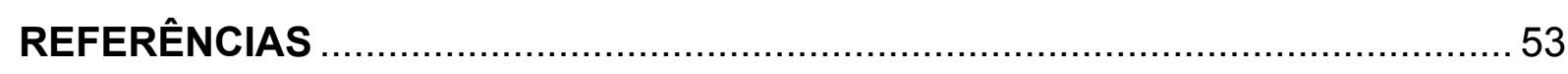

APÊNDICES

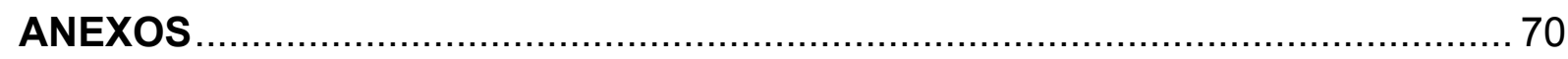




\section{INTRODUÇÃO}

Com a redução na velocidade de progressão da doença cárie, além da simples presença da lesão, é importante que se avalie a atividade de cárie, ou seja, a chance de progressão da doença $(1,2)$, que representa um parâmetro relativo ao diagnóstico da doença, permitindo, assim, que se estabeleça a modalidade de tratamento mais adequada (3-5). Além disso, esse tipo de medida dinâmica permite diferenciar a situação atual da doença de sinais pregressos que ainda estejam presentes (2). Por fim, pode ser útil também na classificação inicial de pacientes a serem incluídos em estudos clínicos controlados (6).

Baseados nas características diferenciais entre as lesões de cárie ativas e inativas, alguns critérios visuais têm sido propostos para essa finalidade, já que, atualmente, o método clínico mais efetivo para a avaliação da atividade das lesões é a inspeção visual (7-9). Entretanto, o exame de inspeção visual é um método subjetivo e depende da decisão do examinador (10). A utilização de métodos objetivos e quantitativos, que tem sido estudada na tentativa de aprimorar e padronizar a deteç̧ão de lesões de cárie e a determinação da severidade destas, poderia ser uma alternativa a esses exames subjetivos.

A fluorescência a laser é um dos métodos objetivos testados nesse sentido. Trata-se de método baseado na captação da fluorescência emitida pelo dente após a emissão de uma luz proveniente de um laser de diodo. Atualmente dois aparelhos baseados nesse método estão disponíveis no mercado: o DIAGNOdent e o DIAGNOdent pen. Esses aparelhos detectam especialmente a fluorescência proveniente da parte orgânica da lesão de cárie. Os principais responsáveis pelo aumento da fluorescência após excitação com a luz nesse comprimento de onda parecem ser metabólitos bacterianos, provavelmente porfirinas (11-13). Dessa forma, como lesões ativas de cárie são mais infectadas que as lesões inativas (3), a fluorescência 
a laser poderia ser um bom adjunto ao exame visual na avaliação da atividade das lesões de cárie.

Apesar de esse método ter sido extensivamente estudado para detecção da profundidade de lesões de cárie poucos estudos têm se atido à avaliação da atividade das lesões com esse método (14-16). Estudo prévio realizado com a primeira linha de aparelhos (DIAGNOdent) demonstrou, clinicamente, que este método mesmo com a secagem padrão de 3s já foi capaz de verificar diferenças no status de lesões de cárie cavitadas. No entanto, para lesões não cavitadas, a variação na leitura de fluorescência captada após diferentes tempos de secagem sugeriram que tal metodologia poderia ser uma alternativa para diferenciar lesões de cárie ativas e inativas (14).

Como a primeira linha desses aparelhos vem sendo largamente substituída por seus sucessores mais modernos e as duas versões têm mostrado diferenças significativas quanto à performance (dados não publicados), extrapolamos a possibilidade de testar a metodologia de secagem proposta inicialmente, utilizando essa nova versão (DIAGNOdent pen). O teste de maior tempo de secagem tornou-se uma possibilidade para tentar diferenciar do status de atividade dessas lesões mais iniciais, em uma leitura única, não dependendo, assim, de duas leituras para verificar a variação entre elas, como observado em estudo prévio (14). Supôs-se que aumentando o tempo de secagem, ocorreria maior concentração dos metabólitos bacterianos existentes nas lesões não cavitadas ativas, permitindo a diferenciação entre essas e as lesões inativas com a mesma condição de integridade superficial. Isso permitiria que, em uma única sessão, pudesse se ter a avaliação objetiva das lesões de cárie quanto ao seu status de atividade, o que poderia facilitar no monitoramento dessas lesões, além de eliminar variações interexaminadores. 


\section{REVISÃO DE LITERATURA}

\subsection{DIAGNÓSTICO DE ATIVIDADE DA LESÃO DE CÁRIE}

Apesar da importância em se avaliar a atividade de cárie, essa é uma área pouco desenvolvida e pesquisada dentro da Cariologia (6), especialmente envolvendo dentes decíduos $(10,17)$. Alguns índices de inspeção visual têm sido propostos para detectar a presença das lesões e tornar o exame visual menos subjetivo. O International Caries Detection and Assessment System (ICDAS) é um índice visual recentemente desenvolvido, com o propósito de facilitar comparações em levantamentos epidemiológicos de cárie, pesquisa, ensino e até mesmo na clínica diária (18). Entretanto, isolado, ele é apenas capaz de avaliar a profundidade das lesões. Portanto, critérios adjuntos têm sido usados para a avaliação da atividade. Um deles consiste na ponderação mental, pelo examinador, das características táteis e visuais associadas à atividade da lesão de cárie, o qual chega finalmente à conclusão se a lesão é ativa ou inativa Outro critério adicional que foi criado para ser utilizado em associação com o ICDAS é o Lesion Activity Assessment (LAA), que é baseado na combinação de parâmetros clínicos relacionados à lesão como: a aparência visual da lesão (ICDAS-II), propensão local à estagnação de placa e a textura da superfície. Para cada um deles, há pontos específicos para serem atribuídos, sendo a soma desses pontos a forma de classificação dessas lesões, quanto à atividade (19). Apesar de já estarem descritos na literatura (20) há alguns anos, os índices visuais para avaliação da atividade das lesões de cárie, existem poucos estudos validando os métodos em dentes decíduos $(21,22)$.

A quantificação de fluorescência induzida pela luz também tem se mostrado promissora para essa finalidade. Outro método baseado na quantificação de fluorescência induzida pela luz (Quantitative light-induced fluorescence - QLF) tem sido estudado como instrumento para quantificação 
e monitoramento das lesões de cárie. Esse aparelho registra a fluorescência emitida pelos produtos bacterianos presentes no biofilme dentário (fluorescência vermelha), além da fluorescência emitida pelos tecidos cariados (fluorescência verde - fluorescência intrínseca mineral e fluorescência vermelha). Esse sistema usa uma lâmpada de xenônio que emite luz violeta-azul com comprimento de onda de $405 \mathrm{~nm}$ e as imagens são analisadas através de um software que mede o grau de perda de fluorescência entre o esmalte sadio e desmineralizado (23). A emissão de fluorescência vermelha pelo biofilme bacteriano quando excitado pelo QLF já foi positivamente verificada e a sua efetividade em associar desmineralização, por meio da fluorescência verde, com atividade de cárie também foi mostrada em superfícies lisas (24).

Outra dificuldade em relação aos estudos referentes à atividade de cárie é a carência de métodos propostos para validação desse tipo de parâmetro nas lesões de cárie $(25,26)$, sendo, portanto, um assunto ainda bastante controverso.

Alguns estudos têm utilizado a validação preditiva ou de constructo dos métodos de diagnóstico para avaliação da atividade de cárie, frente à impossibilidade de se realizar a validação de critério na amostra estudada (27-29). Entretanto, esse tipo de validação demanda o acompanhamento longitudinal dos pacientes, o que dificulta seu emprego em alguns tipos de estudo, bem como incorre na maior possibilidade de perda da amostra durante o seguimento dos sujeitos. A validação concorrente, que usa como referência outro método consagrado, como no caso o exame visual, para validar um método novo também tem sido empregada em alguns trabalhos $(14,24,30)$. Entretanto, nesse caso, há uma possibilidade de, em se testando um método mais acurado, acabar se superando o próprio padrão de referência (31).

Para validação de critério da atividade das lesões de cárie, os métodos comumente utilizados se baseiam no $\mathrm{pH}$ das lesões de cárie. Um corante indicador de $\mathrm{pH}$, vermelho de metila a $1 \%$, tem sido usado em alguns estudos para validar atividade das lesões de cárie $(8,22,32)$. Esse corante altera sua 
cor por volta do pH 5,5 (8, 32). Essa alteração provavelmente está mais relacionada à formação de um sal ácido no processo de desmineralização dos tecidos dentários, do que propriamente ao ácido livre presente nesses tecidos (32). Outros métodos para avaliação in vitro da atividade de lesões de cárie têm sido propostos, os quais se baseiam na aferição direta do $\mathrm{pH}$ das lesões de cárie com microscópio e microsensor de $\mathrm{pH}(33,34)$.

Embora não empregadas rotineiramente em estudos de atividade de cárie, outras propostas de validação da atividade de lesões de cárie, além da aferição do $\mathrm{pH}$, poderiam ser aventadas, tendo por base o mecanismo de fisiopatologia das mesmas e as características diferenciais entre lesões ativas e inativas. A porosidade, opacidade e rugosidade das lesões de cárie são sabidamente características importantes para se considerar acerca da atividade das lesões (3). Entretanto, a maioria dos trabalhos não adota métodos objetivos para quantificar e validar tais características. Metodologias empregadas em outras áreas afins, para a avaliação desses parâmetros (3542), poderiam, em contrapartida, serem testadas para distinguir lesões de cárie ativas e inativas, a fim de se criar novas metodologias de estudo em atividade de cárie e disponibilizar métodos objetivos de validar os exames realizados na clínica. Para tanto, o estabelecimento de índices e/ou pontos de corte de referência para esses métodos também se torna desejável.

A contribuição de novos métodos para validação da atividade de lesões de cárie é de extrema importância dentro do contexto atual da Odontologia. Entretanto, os métodos acima expostos são empregados apenas para dentes que tenham sido extraídos ou exfoliados. Apesar de os dentes decíduos permitirem que o dente seja examinado na cavidade bucal e após sua exfoliação, validado pelos métodos acima, é, ainda, interessante que métodos para validação de lesões estejam disponíveis para serem adotados na prática clínica. Um material de moldagem (Clinpro Caries Diagnosis, Full Arch Lactic Acid Location, 3M ESPE) que altera sua coloração em áreas de maior produção de ácido láctico pelo biofilme bacteriano foi empregado como forma de se obter validade de constructo para atividade de cárie (19). No entanto, este material não está disponível no mercado 
nacional, impossibilitando sua ampla utilização. Um novo material recentemente introduzido no mercado (GC Plaque Indicator Kit, GC), tem como proposta avaliar o $\mathrm{pH}$ do biofilme depositado na superfície dental, o que poderia ser também uma forma de se prever a atividade das lesões de cárie. Alternativa seria a avaliação do tipo de bactérias presentes nessa placa e posterior associação com atividade de cárie (43). Como o método de fluorescência induzida por luz (QLF) é também eficiente na avaliação e quantificação do biofilme bacteriano (44), além de o biofilme maduro estar geralmente mais associado com a fluorescência na faixa do vermelho no comprimento de onda utilizado, tal equipamento poderia também ser um recurso associação na validação de atividade das lesões. Por outro lado, também não está claro na literatura vigente a associação de nenhum desses métodos, com outros métodos laboratoriais disponíveis para validação do mesmo parâmetro.

Outro aspecto a ser considerado no que tange a estudos de atividade de lesões de cárie são as metodologias empregadas nesse tipo de estudo. Por ser um aspecto dinâmico, a melhor maneira de se estudar método de diagnóstico de atividade de cárie seria através de estudos clínicos, que permitem o acompanhamento das lesões, permitindo verificar se o diagnóstico fora relacionado com o desfecho esperado.

\subsection{O USO DA FLUORESCÊNCIA A LASER NA CARIOLOGIA}

A fluorescência ocorre a partir da interação de ondas eletromagnéticas com determinadas moléculas, que, num primeiro momento são excitadas e, ao retornarem ao seu estado de origem, fluorescem, ou seja, liberam luz, a qual pode ou não estar dentro do espectro visível da luz. A fluorescência emitida pelos tecidos dentários vem sendo pesquisada há algum tempo (4547). 
Em 1998, pesquisadores verificaram emissão de fluorescência capaz de diferenciar tecido hígido de tecido cariado(48). Baseado neste princípio, foi desenvolvido um novo aparelho para o diagnóstico das lesões de cárie (DIAGNOdent, Kavo, Biberach, Alemanha). Este aparelho baseia-se na emissão de laser do tipo diodo (AsGalP), com comprimento de onda de $655 \mathrm{~nm}$ e posterior captação pelo aparelho da fluorescência emitida pelos tecidos duros. Segundo esses autores, a fluorescência emitida nesse comprimento de onda, diferentemente do exposto pela literatura até então, é maior para tecidos cariados que para tecidos hígidos. Apesar de qualquer fluorescência ser capaz de diferenciar tecidos doentes de sadios, o comprimento de onda utilizado pelo DIAGNOdent consegue penetrar em profundidade, produzindo dois níveis de fluorescência responsáveis pela diferenciação desses dois tecidos $(12,48)$.

Tecidos moles, sangue e hidroxiapatita não emitem fluorescência quando expostos ao comprimento de onde emitido pelo DIAGNOdent. Por outro lado, a fluorescência tende a aumentar conforme a coloração de dentes hígidos e com o aumento de conteúdo bacteriano e seus metabólitos, sem alterar-se quando o dente é submetido a desmineralização ou remineralização artificial $(12,49)$. Adicionalmente, um estudo que utilizou dentes imersos em em hipoclorito de sódio, observou uma redução significativa nas leituras pelo aparelho, reforçando a influência da parte orgânica das lesões no funcionamento desse método de diagnóstico de cárie (50). Logo, a fluorescência basal emitida por um dente provavelmente está relacionada à combinação de sua matriz inorgânica com baixa concentração de moléculas orgânicas ao passo que a observada no processo carioso está mais relacionada ao aumento na concentração de metabólitos bacterianos que propriamente à desintegração da parte cristalina do mesmo (12).

Em relação ao processo de calibração do aparelho, é necessário que seja feita uma calibração inicial em um padrão cerâmico específico para padronizar as leituras e eliminar possíveis interferências do ambiente, pois o aparelho trabalha com as medidas em unidades arbitrárias (12). Como o aparelho pode alterar suas leituras dependendo do grau de coloração do 
dente, é importante também que seja feita uma calibração, prévia ao exame propriamente dito, em uma superfície lisa hígida do dente, para que o valor da fluorescência natural do dente possa ser descontado das futuras leituras calibração individual (12). Alguns estudos têm mostrado que a falta dessa calibração resulta em alterações nas leituras do aparelho tanto em dentes permanentes (51), como em dentes decíduos (52). Para dentes decíduos, entretanto, não houve influência dessas alterações na performance do método (52). Para dentes permanentes, não foi verificada o desempenho do método na ausência da calibração individual (51). Apesar desses resultados, a utilização da calibração individual em pesquisas tem sido encorajada, para se obter uma maior padronização dos resultados (52).

$\mathrm{Na}$ literatura, encontra-se certa unanimidade no que diz respeito à reprodutibilidade do método, visto que o mesmo tem apresentado concordância intra e inter examinadores de boa a excelente, variando entre 0,42 e 0,99 (53-71). Entretanto, sabe-se que o grau de experiência pode influenciar no desempenho do método, ainda de que maneira reduzida em comparação os demais métodos disponíveis para diagnóstico de cárie $(60$, $63,72)$.

Por outro lado, os trabalhos nessa área mostram-se controversos em relação ao desempenho do método. Alguns autores encontraram resultados que apontam para a alta sensibilidade do mesmo, ou seja, alta capacidade de identificar doença $(53,54,58,60,67,68,73,74)$ ao passo que outros verificaram alta especificidade, ou seja, apresentariam baixo número de falsos-positivos $(57,59,61,63,69,71,75-78)$. Em geral, a maioria dos trabalhos em dentes permanentes mostra que o método tende a ter maior sensibilidade que especificidade e, em dentes decíduos, especificidade semelhante ou discretamente maior que a sensibilidade (79).

A utilização de pontos de corte distintos pode ser um dos motivos passíveis de explicarem a divergência de resultados quanto ao desempenho do método $(58,64,69,77,80)$. A escolha do ponto de corte deve, portanto, depender do que se espera do método $(56,77)$. Se o objetivo for associá-lo ao exame visual, o ideal é que o ponto de corte melhore a sensibilidade do 
método. Se o objetivo é empregar o método isoladamente, recomenda-se que os valores de sensibilidade e especificidade encontrem um equilíbrio de forma a se obter acurácia satisfatória. Entretanto, em populações com baixa prevalência de cárie, métodos mais específicos são preferíveis (77).

Outros fatores ligados à aplicação do método também podem interferir na avaliação da performance do mesmo. O procedimento de secagem é uma dessas possíveis variáveis. Alguns autores observaram que a secagem breve (aproximadamente 3 segundos) não alterou as leituras do aparelho de fluorescência a laser quando comparadas às leituras com os dentes úmidos (67, 81). A secagem prolongada alterou as leituras com o aparelho, sem, entretanto alterar o desempenho do mesmo $(71,81)$. Quando isso não ocorre, a tendência é que, para lesões em dentina, haja maior a especificidade em dentes úmidos que em dentes secos (67). Se considerados dentes desidratados, a sensibilidade do método tende a ser superestimada (81). Em linhas gerais, os autores concluíram que o DIAGNOdent tolera bem a presença de saliva sobre o dente no momento do exame $(67,71,81)$

A pigmentação de fossas e fissuras também pode alterar a leitura do DIAGNOdent, pois pode ser lida pelo aparelho como um aditivo, levando à redução na especificidade $\mathrm{e}$, portanto, muitas vezes, requerer o estabelecimento de pontos de corte superiores $(60,75)$. Dentes com lesões histologicamente em terço interno de esmalte ou externo de dentina, mas com pigmentação, induziram a leituras compatíveis com profundidade maior que a encontrada; contribuindo, assim para o aumento de números falsopositivos. Ainda, lesões com profundidades semelhantes mostraram valores para o DIAGNOdent maiores quando eram pigmentadas extrinsecamente (62). A interferência da pigmentação das fissuras nas leituras do aparelho de fluorescência a laser pode ser um ponto desfavorável para seu uso na avaliação da atividade de lesões de cárie (14).

Além disso, um fator importante que pode exercer influência nos resultados de diferentes estudos é relacionado aos procedimentos de biossegurança, uma vez que tanto a proteção das pontas com película de 
PVC, como os procedimentos de autoclavagem alteram as medições com o aparelho $(82,83)$.

Poucos estudos com dentes decíduos têm sido realizados, de forma geral, na área de diagnóstico de cárie (10). Da mesma forma, isso também é observado para o método da fluorescência a laser (79).

Alguns estudos têm se preocupado em aplicar 0 método paralelamente em dentes decíduos e permanentes $(54,55,62,77)$.

Alguns autores encontraram pontos de corte bastante próximos entre dentes decíduos e permanentes, tanto in vitro $(62,77)$, como in vivo $(54)$. In vitro, a fluorescência a laser mostrou melhor sensibilidade para lesões em dentina do que para esmalte, o que pode estar associado com o menor tempo de armazenamento do dente e também com a menor espessura do esmalte decíduo (77). A performance da fluorescência a laser para decíduos, in vivo, não foi, entretanto, avaliada (54).

Dentre os estudos que avaliaram dentes decíduos isoladamente, verificou-se boa reprodutibilidade e alta sensibilidade do método, sendo o melhor desempenho observado para lesões restritas ao esmalte (66). Os autores consideraram tais resultados semelhantes a estudos com permanentes também conduzidos pelos mesmos (67).

Outros estudos, entretanto, verificaram que a performance do método, in vitro e in vivo, foi melhor para deteç̧ão de lesões em dentina do que em esmalte $(52,77,81,84)$. Um deles verificou também que o método detecta melhor as lesões avançadas em esmalte, que as lesões iniciais (84). 0 método em questão está mais associado à leitura da porção orgânica das lesões (12), logo, melhor desempenho do método tende a ser observado para as lesões mais avançadas, já que as mesmas apresentam maior quantidade de metabólitos bacterianos (78).

Alguns estudos prévios têm mostrado que o aparelho não quantifica adequadamente a perda mineral das lesões iniciais, estando mais associado com a profundidade das lesões (85-88). A associação do método com um 
corante fluorescente (tetrametilpiridilporfirina) melhorou o desempenho do aparelho na detecção e quantificação de lesões iniciais de cárie em esmalte (89). Essa associação foi também utilizada para mensuração de lesões induzidas artificialmente ao redor de braquetes ortodônticos, mostrando boa correlação também com a perda mineral das lesões (90).

Como a fluorescência a laser é um método quantitativo e com alta reprodutibilidade, poderia ser utilizado em estudos para acompanhamento da progressão ou regressão de lesões de cárie (16, 91-93). Alguns desses estudos utilizaram o aparelho de fluorescência para verificação da atividade das lesões de cárie em superfícies lisas $(15,16)$, sendo que um deles monitorou a remineralização de lesões de cárie ao redor de braquetes in vivo (16) e outro avaliou clinicamente uma série de lesões classificadas visualmente em ativas e inativas, sendo capaz de diferenciar tais lesões de acordo com seu status (15).

Em superfície oclusais de dentes decíduos, um estudo in vivo foi conduzido para verificar a habilidade do aparelho em avaliar a atividade das lesões de cárie utilizando diferentes tempos de secagem do dente, 3 segundos e 15 segundos. Os autores concluíram que o tempo de secagem pode ser uma alternativa para melhorar a avaliação da atividade de cárie. Entretanto, um aumento no tempo de secagem foi sugerido para testar essa hipótese (14).

Devido à falta de evidências em relação à utilização do método da fluorescência a laser na avaliação da atividade das lesões de cárie, justificase o objetivo deste estudo. 


\section{PROPOSIÇÃO}

O objetivo do presente estudo in vivo foi testar, baseado em validação concorrente e preditiva, o uso da secagem prolongada por 30s empregada na tentativa de melhorar a habilidade do método de fluorescência a laser em diferenciar o status de atividade de lesões de cárie oclusais em dentes decíduos. Os testes foram realizados usando a medida de fluorescência a laser de forma isolada e também a diferença entre essa medida e a medida obtida após secagem padrão por 3s. 


\section{MATERIAL E MÉTODOS}

Este projeto foi aprovado pelo ao Comitê de Ética em Pesquisa (CEP) da Faculdade de Odontologia da Universidade de São Paulo (FOUSP) (Protocolo 181/2009) (Anexo A).

\subsection{SELEÇÃO DOS SUJEITOS DO ESTUDO}

Foram selecionadas 99 crianças, com idade entre 4 e 14 anos que procuraram o serviço de triagem da disciplina de Odontopediatria da Faculdade de Odontologia da Universidade de São Paulo (FOUSP). Noventa e três crianças (idade média \pm desvio padrão $=7.38 \pm 2.20$ ) concluíram todas as fases do estudo (taxa de resposta positiva de 93,93\%). Foram incluídas crianças com a presença de pelo menos um dente decíduo cuja face oclusal fosse passível de ser avaliada clinicamente. Faces com restaurações, selantes, cavidades evidentes de cárie ou outros tipos de defeitos de formação foram excluídas. Estes pacientes, bem como seus responsáveis, receberam informações por escrito sobre a pesquisa, sendo que, aceitando participar espontaneamente da mesma, assinaram o termo de consentimento livre e esclarecido (TCLE) (Apêndice A). Após a assinatura do TCLE foram iniciados os exames pertinentes à pesquisa e os formulários em anexo foram utilizados para a coleta de dados (Apêndice B).

Previamente a todos os exames, os dentes selecionados receberam profilaxia com pedra-pomes e água com auxílio de uma escova de Robinson, montadas em turbina de baixa-rotação. As crianças foram examinadas em consultório odontológico, com auxílio de refletor e ar da seringa tríplice. 


\subsection{EXAME COM MÉTODO DE FLUORESCÊNCIA INDUZIDA POR LASER (DIAGNODENT PEN)}

Após calibração do aparelho na superfície sadia e breve secagem do sítio com seringa tríplice (3 segundos), um examinador, treinado para utilizar o aparelho, realizou duas medições com o DIAGNOdent pen varrendo toda a superfície oclusal e anotando o valor de pico de cada medição. Esse procedimento foi realizado duas vezes por superfície e, ao final, a média dessas duas medidas foi considerada. Novas medições foram realizadas após reidratação do dente por 1 minuto. Nessa ocasião, os dentes foram examinados com o mesmo método após 30 s de secagem com seringa, seguindo a mesma sistemática descrita acima.

Assim, foram obtidos os valores absolutos das medições iniciais após 3s (controle) e 30s de secagem. Também foi calculada a diferença entre a primeira e a segunda medição (DIF 30s-3s) para verificar o aumento da segunda leitura com relação à primeira. Essa metodologia de secagem foi adaptada, aumentando o tempo da segunda secagem, para testar a hipótese aventada em estudo prévio do nosso grupo de trabalho de que a ampliação do tempo de secagem poderia distinguir melhor o status de atividade das lesões (14).

\subsection{VALIDAÇÃO CONCORRENTE}

Para a validação concorrente do método de fluorescência a laser na avaliação da atividade das lesões de cárie, foi utilizado o índice de inspeção visual ICDAS associado aos critérios visuais e tácteis característicos por serem diferenciais entre lesões de cárie (18-20).

O ICDAS, classifica as lesões em relação à presença de alterações no esmalte compatíveis com lesões de cárie (opacidade ou pigmentação), 
presença de integridade ou descontinuidade da superfície e exposição de dentina adjacente (Figura 4.1). A avaliação da atividade das lesões foi realizada através da ponderação mental das características clinicas da lesões, levando em conta parâmetros consagrados na literatura no que tange à diferenciação de lesões quanto ao seu status de atividade (20) (Figura 4.2). Segundo esse critério, dependendo da severidade da lesão, algumas características clínicas deveriam ser avaliadas em conjunto. Se a lesão apresentasse maior número de características de uma lesão ativa seria classificada como tal. Por outro lado, se prevalecessem as características de lesões inativas, a lesão seria dita inativa.

\begin{tabular}{|c|c|}
\hline Escore & Critérios de classificação \\
\hline 0 & Nenhuma ou sutil alteração na translucidez do esmalte após secagem de 5s \\
1 & Opacidade dificilmente visível na superfície úmida, mas notável após secagem \\
2 & Opacidade visível sem secagem \\
3 & Cavidade localizada em esmalte opaco ou pigmentado \\
4 & $\begin{array}{r}\text { Sombreamento da dentina subjacente } \\
5\end{array}$ \\
6 & $\begin{array}{r}\text { Cavidade em esmalte opaco ou pigmentado com exposição da dentina } \\
\text { subjacente }\end{array}$ \\
& $\begin{array}{r}\text { Cavidade em esmalte opaco ou pigmentado com exposição da dentina } \\
\text { subjacente, Cavidade envolvendo mais de metade da dentina adjacente. }\end{array}$ \\
\hline
\end{tabular}

Figura 4.1 - Critério visual ICDAS (18) 


\begin{tabular}{|c|c|c|}
\hline $\begin{array}{c}\text { Código do } \\
\text { ICDAS }\end{array}$ & Lesão Ativa (a) & Lesão inativa (i) \\
\hline 1,2 ou 3 & $\begin{array}{c}\text { Esmalte com opacidade esbranquiçada ou } \\
\text { amarelada, perda de brilho, que parece } \\
\text { rugoso ao se passar a sonda suavemente } \\
\text { sobre a superfície. Lesão localizada em } \\
\text { região com estagnação de placa (fossas e } \\
\text { fissuras, perto da margem gengival, } \\
\text { superfícies proximais abaixo do ponto de } \\
\text { contato }\end{array}$ & $\begin{array}{c}\text { Esmalte esbranquiçado, } \\
\text { amarronzado ou enegrecido, com } \\
\text { aspecto brilhante, duro e liso } \\
\text { quando se passa a sonda } \\
\text { suavemente sobre a superfície. } \\
\text { Para superfícies lisas, essas lesões } \\
\text { tipicamente estão distantes da } \\
\text { margem gengival. }\end{array}$ \\
\hline 4 & Provavelmente ativa & Cavidade mostrando ao fundo \\
\hline 5 & Cavidade mostrando ao fundo tecido \\
amolecido ao se passar a sonda. & $\begin{array}{c}\text { tecido endurecido ao se passar a } \\
\text { sonda, além de aspecto brilhante } \\
\text { (sem opacidades). }\end{array}$ \\
\hline
\end{tabular}

Figura 4.2 - Critério visual e táctil para a classificação da atividade das lesões de cárie (20)

Na validação concorrente, para contemplar os critérios visuais e tácteis acima descritos, a sonda periodontal tipo OMS (ponta romba) foi utilizada de forma suave, em conjunto com um espelho clínico, para avaliação das superfícies oclusais selecionadas. Após treinamento e calibração iniciais, dois examinadores experientes na utilização dos índices propostos, de forma independente, realizaram o exame das lesões usando os critérios acima descritos. Após a avaliação de cada superfície, o maior escore correspondente à mesma, para cada um dos índices foi anotado, bem como a classificação da lesão em relação à sua atividade. Um dos examinadores repetiu os exames em $10 \%$ da amostra após uma semana.

Após a inspeção visual independente dos dois examinadores, os resultados foram confrontados. Caso houvesse concordância, esse foi considerado o status da lesão. Em caso de discordância, um novo exame em conjunto foi realizado para se chegar a um consenso. Esse consenso foi adotado como referência para todas as análises realizadas. 
Os exames visuais constantes dessa validação foram finalizados antes dos exames com o aparelho de fluorescência a laser para evitar que os examinadores fossem influenciados pelas possíveis leituras.

\subsection{VALIDAÇÃO PREDITIVA}

Para a validação preditiva, 19 pacientes, com idade entre 6 e 7 anos (media \pm desvio padrão $=6.38 \pm 0.9$ ) foram reexaminados após um ano da realização dos exames iniciais, totalizando 105 superfícies oclusais.

Para esse exame os mesmos critérios descritos durante a validação concorrente foram utilizados. Em seguida, comparamos a condição inicial com a final, a fim de determinar os seguintes desfechos:

- progressão das lesões de cárie: para esse desfecho consideramos os escores do ICDAS iniciais e finais. No caso de ter havido mudança para um escore maior, considerou-se progressão. O mesmo ocorreu se o dente havia sido restaurado. Os outros casos foram considerados não progressão.

- melhora na condição da superfície: nesse desfecho, levamos em consideração a atividade das lesões avaliada por exame visual e táctil. Se as superfícies inicialmente eram classificadas como ativas e passassem a inativas, isso foi considerado uma melhora. Se mantivesse seu status ou piorassem, seriam consideradas, para esse desfecho, como não melhora. No caso de dentes que tivessem sido restaurados, mas houvesse ausência de atividade de cárie na mesma superfície, considerou-se também melhora.

- piora na condição da superfície: para esse desfecho, também consideramos atividade das lesões de cárie, mas dicotomizando as ocorrência de forma distinta. Lesões inativas ou superfícies hígidas que se tornaram ativas foram consideradas casos de piora. 
Casos que se mantiveram ou que melhoraram foram classificados, nesse desfecho, como não piora.

\subsection{ANÁLISE DOS DADOS}

As reprodutibilidades intra e interexaminador dos exames visuais realizados nesse estudo foram calculadas pelo teste de Kappa ponderado para os escores do ICDAS e de Cohen's Kappa para a classificação das lesões de acordo com seu status de atividade e para o método de fluorescência a laser foi utilizado o coeficiente de correlação intraclasse (ICC). Esses valores foram calculados com $95 \%$ de intervalo de confiança (95\% IC).

Para a avaliação se o método seria capaz de diferenciar lesões ativas de lesões inativas, foram consideradas as medições após $3 \mathrm{~s}$ e $30 \mathrm{~s}$ de secagem, além da diferença entre essas medidas (DIF 30s-3s). Para isso, foram utilizadas análises de regressão linear multinível, já que mais de um dente foi avaliado na mesma criança. Assim, como níveis, consideramos o dente ( $1^{\circ}$ nível) e a criança ( $2^{\circ}$ nível). As leituras do aparelho após cada tempo de secagem e também a DIF $30 \mathrm{~s}-3 \mathrm{~s}$ foram escolhidos como desfechos para essas análises.

Delineamos, então, dois modelos de regressão distintos. Em um deles buscamos verificar a associação entre a fluorescência a laser e a profundidade clínica + atividade das lesões de cárie. As lesões com escores 1 a 3 foram consideradas clinicamente em esmalte e aquelas com escores 4 a 6 foram classificadas como em dentina. Além disso, o status de atividade das mesmas foi combinado compondo as seguintes categorias: sadios, lesões em esmalte inativas, lesões em esmalte ativas, lesões em dentina inativas e lesões em dentina ativas. Como havia apenas um caso de lesão inativa evidente em dentina, a mesma não foi considerada nessa análise. As lesões inativas em esmalte foram escolhidas como variável de referência. 
No outro modelo de regressão, foi verificada a associação entre as leituras de fluorescência a laser e a integridade superficial + atividade das lesões. Nessa análise, as lesões escore 1 e 2 foram classificadas como não cavitadas e as demais como cavitadas. Essa abordagem foi feita, pois todas as lesões escore 4 examinadas apresentavam microcavitação ou descontinuidade superficial, podendo ser colocadas no grupo das lesões cavitadas. O status de atividade das mesmas foi combinado compondo as seguintes categorias: sadios, lesões não cavitadas inativas, lesões não cavitadas ativas, lesões cavitadas inativas e lesões cavitadas ativas. Nesse modelo, a categoria estabelecida como referência foi a de lesões não cavitadas inativas.

Ambos os modelos foram testados com e sem o ajuste pela pigmentação das lesões de cárie não cavitadas (lesões pigmentadas vs. lesões brancas).

Quando foi considerada a validação preditiva, modelos de regressão logística multinível foram usados para verificar a associação da progressão das lesões de cárie com as leituras de fluorescência a laser após 3s e 30s, bem como com a DIF 30s-3s. Outros modelos foram testados considerando a melhora ou piora no status de atividade da superfície, conforme definido na seção anterior. O risco relativo com intervalo de confiança de 95\% (RR; 95\% IC) foi calculado para cada tempo de secagem e também para a diferença, considerando cada um dos desfechos descritos. Os níveis utilizados nessas análises foram os mesmos descritos para as análises de regressão linear.

O nível de significância adotado para todos os testes empregados foi $p<0.05$. 


\section{RESULTADOS}

A reprodutibilidade intra e interexaminador relativas ao índice visual para avaliação de profundidade e severidade foram, respectivamente, de 0,97 (95\% IC: 0,95 a 0,99) e 0,94 (95\% IC: 0,93 to 0,97 ). Já, para a avaliação de atividade, encontrou-se um valor de Kappa de 0,85 (95\% IC: 0,73 a 0,98), para a reprodutibilidade intra-examinador e de 0,87 (95\% IC: 0,83 a 0,91), para a reprodutibilidade interexaminador. $O$ método de fluorescência a laser resultou em valores de ICC de 0,91 (95\% IC: 0,90 a 0,93) para reprodutibilidade intra-examinador.

As tabelas 5.1 e 5.2 mostram as médias das leituras de fluorescência a laser obtidas nos diferentes limiares utilizados neste estudo determinados a partir do método visual utilizado para avaliação de severidade e atividade das lesões. Pode-se perceber discreta diferença nos valores médios das leituras obtidas após $3 \mathrm{~s}$ e $30 \mathrm{~s}$ de secagem, variando, em média, de 0,6 a 3,8 unidades arbitrárias.

Tabela 5.1 - Médias \pm desvios-padrão das leituras obtidas com o aparelho de fluorescência a laser (Ddpen) considerando as diferentes categorias de profundidade clínica associada com a atividade das lesões de cárie utilizando método visual consagrado

\begin{tabular}{lcccc}
\hline & HÍGIDO & \multicolumn{2}{c}{ ESMALTE } & DENTINA* \\
& & inativa & ativa & ativa \\
\hline DDpen 3s & $4,0 \pm 9,9$ & $21,9 \pm 23,3$ & $19,9 \pm 25,0$ & $62,0 \pm 26,2$ \\
DDpen 30s & $4,6 \pm 11,6$ & $23,9 \pm 24,6$ & $22,4 \pm 26,4$ & $65,0 \pm 28,8$ \\
\hline DIF 30s-3s* & $0,6 \pm 4,0$ & $2,0 \pm 8,4$ & $2,5 \pm 7,2$ & $2,9 \pm 13,1$
\end{tabular}

* A categoria "dentina inativa" não está contemplada na tabela pois havia, na amostra, apenas uma superfície apresentava lesão com comprometimento clinicamente evidente da dentina e que estivesse também inativa.

${ }^{* *}$ Médias e desvio-padrão das diferenças entre as leituras obtidas após 30 s de secagem e após $3 \mathrm{~s}$ de secagem. 
Tabela 5.2 - Médias \pm desvios-padrões das leituras obtidas com o aparelho de fluorescência a laser (Ddpen) considerando as diferentes categorias de integridade superficial associada com a atividade das lesões de cárie utilizando método visual consagrado

\begin{tabular}{cccccc}
\hline & \multicolumn{3}{c}{ NÃO CAVITADAS } & \multicolumn{2}{c}{ CAVITADAS } \\
& HÍGIDO & INATIVA & ATIVA & INATIVA & ATIVA \\
\hline DDpen 3s & $4,0 \pm 9,9$ & $17,8 \pm 18,4$ & $12,1 \pm 14,9$ & $41,7 \pm 32,4$ & $59,5 \pm 28,1$ \\
DDpen 30s & $4,6 \pm 11,6$ & $19,7 \pm 20,4$ & $14,2 \pm 16,1$ & $43,5 \pm 32,3$ & $63,4 \pm 29,4$ \\
\hdashline DIF 30s-3S* & $0,6 \pm 4,0$ & $2,0 \pm 8,9$ & $2,0 \pm 6,6$ & $1,7 \pm 5,6$ & $3,8 \pm 11,1$ \\
\hline \multicolumn{7}{c}{ "Médias e desvio-padrão das diferenças entre as leituras obtidas após 30s de secagem e após 3 s de } \\
\multicolumn{4}{c}{ secagem. } \\
\hline
\end{tabular}

As superfícies sadias foram associadas a menores valores de fluorescência a laser quando comparadas a lesões inativas clinicamente em esmalte ou lesões inativas não cavitadas (Tabelas 5.3 e 5.4). No entanto, quando usado a DIF 30s-3s nenhuma diferença entre as lesões iniciais e os sítios sadios foi evidenciada (Tabela 5.5).

Considerando as lesões clinicamente em esmalte, não houve diferença estatisticamente significante na magnitude das leituras de fluorescência a laser entre lesões ativas e inativas, independentemente do tempo de secagem utilizado (Tabela 5.3). Por outro lado, considerando apenas as lesões não cavitadas, observaram-se maiores leituras médias para as lesões de cárie inativas do que para as ativas (Tabela 5.4), efeito que desapareceu quando o a análise foi ajustada pela pigmentação das lesões não cavitadas. De fato, lesões pigmentadas apresentaram maiores leituras de fluorescência a laser comparadas às lesões não pigmentadas (Tabela 5.4) e podem ter influenciado nessas leituras. 
Tabela 5.3 - Análise de regressão linear de multinível da associação entre a aparelho de fluorescência a laser (DDpen) com atividade e profundidade clínica

\begin{tabular}{lccccc}
\hline \multirow{2}{*}{ Efeitos fixos } & \multicolumn{2}{c}{ Modelo nulo } & \multicolumn{3}{c}{ Modelo final } \\
\cline { 2 - 6 } & $\boldsymbol{\beta}$ & EP & $\boldsymbol{\beta}$ & EP & $\mathbf{p}$ \\
\hline DDpen 3s & & & & & $<0,001^{*}$ \\
\hline Intercepto & 20,163 & 1,660 & 21,255 & 2,091 & \\
\hline Esmalte Inativa & & & & & \\
Sadio & & $-15,396$ & 2,767 & $<0,001$ \\
Esmalte ativa & & $-0,632$ & 2,431 & 0,794 \\
Dentina ativa & & & 39,630 & 4,382 & $<0,001$ \\
\hline
\end{tabular}

Efeitos randômicos

\begin{tabular}{ccc} 
Variância do $1^{\circ}$ nível & $157,15(37,46)$ & $83,08(23,73)$ \\
Variância do $2^{\circ}$ nível & $495,36(34,03)$ & $400,00(27,45)$ \\
\hline & 4748,71 & 4607,45
\end{tabular}

\begin{tabular}{|c|c|c|c|c|c|}
\hline Deviance & \multicolumn{2}{|c|}{4748,71} & \multicolumn{2}{|c|}{4607,45} & \multirow[b]{2}{*}{$<0,001^{*}$} \\
\hline DDpen 30 seg & & & & & \\
\hline Intercepto & 22,345 & 1,803 & 23,385 & 2,256 & \\
\hline \multicolumn{6}{|l|}{ Esmalte Inativa } \\
\hline Sadio & & & $-16,575$ & 2,910 & $<0,001$ \\
\hline Esmalte ativa & & & $-0,116$ & 2,563 & 0,964 \\
\hline Dentina ativa & & & 41.062 & 4,609 & $<0,001$ \\
\hline
\end{tabular}

Efeitos randômicos

$\begin{array}{lcc}\text { Variância do } 1^{\circ} \text { nível } & 193,59(44,37) & 117,35(29,81) \\ \text { Variância do } 2^{\circ} \text { nível } & 541,72(37,20) & 431,12(29,61) \\ & 4801,72 & 4659,69\end{array}$

Deviance

$\beta=$ Coeficiente de regressão linear; EP = erro padrão

* Valor de p do modelo final calculado pelo teste da razão de máxima verossimilhança. Demais valores de $p$ se referem à significância das categorias em relação à categoria de referência.

A categoria sublinhada é a categoria da variável independente usada como referência no modelo de regressão. 
Tabela 5.4 - Análise de regressão linear de multinível da associação entre a aparelho de fluorescência a laser (DDpen) com atividade e integridade superficial (NC: lesões não cavitadas; Cav: lesões cavitadas)

\begin{tabular}{|c|c|c|c|c|c|}
\hline \multirow{2}{*}{ Efeitos fixos } & \multicolumn{2}{|c|}{ Modelo nulo } & \multicolumn{3}{|c|}{ Modelo final } \\
\hline & $\beta$ & EP & $\beta$ & EP & $p$ \\
\hline DDpen 3s & & & & & $<0,001^{*}$ \\
\hline Intercepto & 20,163 & 1,660 & 21,255 & 2,091 & \\
\hline \multicolumn{6}{|l|}{ NC Inativa } \\
\hline Sadio & & & $-13,133$ & 2,405 & $<0,001$ \\
\hline NC ativa ** & & & $-5,201$ & 2,220 & 0,019 \\
\hline Cav inativa & & & 24,665 & 4,194 & $<0,001$ \\
\hline Cav ativa & & & 40,874 & 2,779 & $<0,001$ \\
\hline \multicolumn{6}{|l|}{ Efeitos randômicos } \\
\hline Variância do $1^{\circ}$ nível & \multicolumn{2}{|c|}{$157,15(37,46)$} & \multicolumn{2}{|c|}{$42,86(14,55)$} & \\
\hline Variância do $2^{\circ}$ nível & \multicolumn{2}{|c|}{$495,36(34,03)$} & \multicolumn{2}{|c|}{$288,27(19,72)$} & \\
\hline Deviance & \multicolumn{2}{|c|}{4748,71} & \multicolumn{2}{|c|}{4432,91} & \\
\hline \multicolumn{5}{|l|}{ Diagnodent 30 seg } & $<0,001^{*}$ \\
\hline Intercepto & 22,345 & 1,803 & 20,367 & 1,995 & \\
\hline \multicolumn{6}{|l|}{ NC Inativa } \\
\hline Sadio & & & $-14,734$ & 2,560 & $<0,001$ \\
\hline NC ativa *** & & & $-5,266$ & 2,371 & 0,026 \\
\hline Cav inativa & & & 23,822 & 4,477 & $<0,001$ \\
\hline Cav ativa & & & 42,184 & 2,957 & $<0,001$ \\
\hline \multicolumn{6}{|l|}{ Efeitos randômicos } \\
\hline Variância do $1^{\circ}$ nível & \multicolumn{2}{|c|}{$193,59(44.37)$} & \multicolumn{3}{|c|}{$63,68(18,50)$} \\
\hline Variância do $2^{\circ}$ nível & \multicolumn{2}{|c|}{$541,72(37.20)$} & \multicolumn{2}{|c|}{$318,15(21,80)$} & \\
\hline Deviance & \multicolumn{2}{|c|}{4801,72} & \multicolumn{2}{|c|}{4496,71} & \\
\hline \multicolumn{6}{|c|}{$\begin{array}{l}\beta=\text { Coeficiente de regressão linear; EP = erro padrão } \\
{ }^{*} \text { Valor de } p \text { do modelo final calculado pelo teste da razão de máxima verossimilhança. Demais valores de } p \text { se } \\
\text { referem à significância das categorias em relação à categoria de referência. } \\
\text { A categoria sublinhada é a categoria da variável independente usada como referência no modelo de regressão. } \\
{ }^{*} \text { Quando a análise foi ajustada pela pigmentação das lesões não cavitadas, não houve diferença entre lesões } \\
\text { não cavitadas ativas em relação às lesões não cavitadas inativas }(\beta=0,258 ; E P=2.764, p=0,924) \text {. Houve } \\
\text { diferença entre lesões pigmentadas comparadas às lesões não pigmentadas }(\beta=10.563 ; \text { EP }=3,245, p= \\
0,045) \text {. } \\
\text { *** Quando a análise foi ajustada pela pigmentação das lesões não cavitadas, não houve diferença entre lesões } \\
\text { não cavitadas ativas em relação às lesões não cavitadas inativas }(\beta=1,350 ; E P=2.937, p=0,646) \text {. Houve } \\
\text { diferença entre lesões pigmentadas comparadas às lesões não pigmentadas }(\beta=12.854 ; \text { EP }=3,448, p< \\
0,001) \text {. }\end{array}$} \\
\hline
\end{tabular}


As lesões em dentina ou cavitadas apresentaram valores de fluorescência maiores que as lesões iniciais (em esmalte ou não cavitadas) (Tabelas 5.3 e 5.4). Além disso, as lesões cavitadas ativas resultaram em medidas de fluorescência significativamente maiores que as lesões cavitadas inativas $(p<0,001)$. O mesmo não pôde ser observado para as lesões em dentina porque, na amostra, havia número insuficiente de dentes com lesões inativas em dentina, não permitindo generalizações.

A DIF 30s-3s não contribuiu na diferenciação de lesões inativas e ativas, nem considerando lesões clinicamente em esmalte, nem apenas as lesões não cavitadas. (Tabela 5.5). As lesões cavitadas ativas tiveram maior leitura de fluorescência a laser que as demais lesões avaliadas (Tabela 5.5). 
Tabela 5.5 - Análise de regressão linear de multinível da associação entre a diferença nas leituras de fluorescência a laser aos 30 s e 3 s (DIF 30s-3s) com atividade e integridade superficial (NC: lesões não cavitadas; Cav: lesões cavitadas)

\begin{tabular}{|c|c|c|c|c|c|}
\hline \multirow{2}{*}{ Efeitos fixos } & \multicolumn{2}{|c|}{ Modelo nulo } & \multicolumn{3}{|c|}{ Modelo final } \\
\hline & $\beta$ & EP & $\beta$ & EP & p \\
\hline $\begin{array}{l}\text { DIF 30s-3s } \\
\text { Profundidade clínica }\end{array}$ & & & & & $0,100^{*}$ \\
\hline Intercepto & 35,450 & 0,342 & 37,056 & 4,553 & \\
\hline \multicolumn{6}{|l|}{ Esmalte inativa } \\
\hline Sadio & & & $-0,085$ & 4,467 & 0,999 \\
\hline Esmalte ativa ** & & & 1,202 & 4,372 & 0,783 \\
\hline Dentina ativa & & & 10,238 & 6,893 & 0,137 \\
\hline \multicolumn{6}{|l|}{ Efeitos randômicos } \\
\hline Variância do $1^{\circ}$ nível & \multicolumn{2}{|c|}{$0,898(1,625)$} & \multicolumn{2}{|c|}{$1,118(2,778)$} & \\
\hline Variância do $2^{\circ}$ nível & \multicolumn{2}{|c|}{$54,594(3,719)$} & \multicolumn{2}{|c|}{$55,356(5,267)$} & \\
\hline Deviance & \multicolumn{2}{|c|}{4748,71} & \multicolumn{2}{|c|}{4432,91} & \\
\hline \multicolumn{5}{|l|}{$\begin{array}{l}\text { DIF 30s-3s } \\
\text { Integridade superficial }\end{array}$} & 0,020 \\
\hline Intercepto & 35,450 & 0,342 & 36,382 & 4,520 & \\
\hline \multicolumn{6}{|l|}{$\underline{\mathrm{NC} \text { Inativa }}$} \\
\hline Sadio & & & 0,029 & 4,430 & 0,999 \\
\hline NC ativa *** & & & 1,076 & 4,332 & 0,803 \\
\hline Cav inativa & & & 0,000 & 0,000 & 1,000 \\
\hline Cav ativa & & & 22,790 & 8,706 & 0,009 \\
\hline \multicolumn{6}{|l|}{ Efeitos randômicos } \\
\hline Variância do $1^{\circ}$ nível & \multicolumn{2}{|c|}{$0,898(1,625)$} & \multicolumn{3}{|c|}{$2,002(2,857)$} \\
\hline Variância do $2^{\circ}$ nível & \multicolumn{2}{|c|}{$54,594(3,719)$} & \multicolumn{2}{|c|}{$53,558(5,112)$} & \\
\hline Deviance & \multicolumn{2}{|c|}{4748,71} & \multicolumn{2}{|c|}{2008,051} & \\
\hline \multicolumn{6}{|c|}{$\begin{array}{l}\beta=\text { Coeficiente de regressão linear; EP = erro padrão } \\
{ }^{*} \text { Valor de } p \text { do modelo final já ajustado pela pigmentação das lesões iniciais e calculado pelo teste da razão de } \\
\text { máxima vero ssimilhança. Demais valores de } p \text { se referem à significância das categorias em relação à } \\
\text { categoria de referência. } \\
\text { A categoria sublinhada é a categoria da variável independente usada como referência no modelo de regressão. } \\
{ }^{*} \text { Houve diferença entre lesões pigmentadas comparadas às lesões não pigmentadas, } p=0,047 \text {, mas isso não } \\
\text { alterou a relação entre lesões em esmalte ativas e inativas. } \\
{ }^{* \star *} \text { Não houve diferença entre lesões pigmentadas comparadas às lesões não pigmentadas }(p=0,085) \text {. }\end{array}$} \\
\hline
\end{tabular}


Entre as crianças reavaliadas após um ano, inicialmente, existiam 25 superfícies hígidas (escore 0 ), 57 superfícies eram escores 1 ou 2, 15 apresentavam escore 3, 2 eram escore 4 e finalmente 6 foram classificadas como escore 5. Dessas, apenas 22 (23\%) superfícies apresentaram progressão das lesões de cárie detectada pelo exame visual, sendo a evolução mostrada na Figura 5.1. Nota-se que a maioria das transições quanto a esse desfecho (45\%) ocorreu a partir de superfícies hígidas que se passaram a apresentar lesões iniciais em esmalte (escore 1) ou ainda, lesões iniciais que progrediram para escores maiores ou foram restauradas (36\%). A tabela 5.6 ilustra os valores médios de fluorescência a laser para os casos em que foi vista progressão das lesões em comparação aos que isso não ocorreu. Independentemente do tempo de secagem prévia, dentes com maiores medidas de fluorescência a laser no início do estudo não tiveram maior risco de apresentar progressão de lesões de cárie (Tabela 5.7).

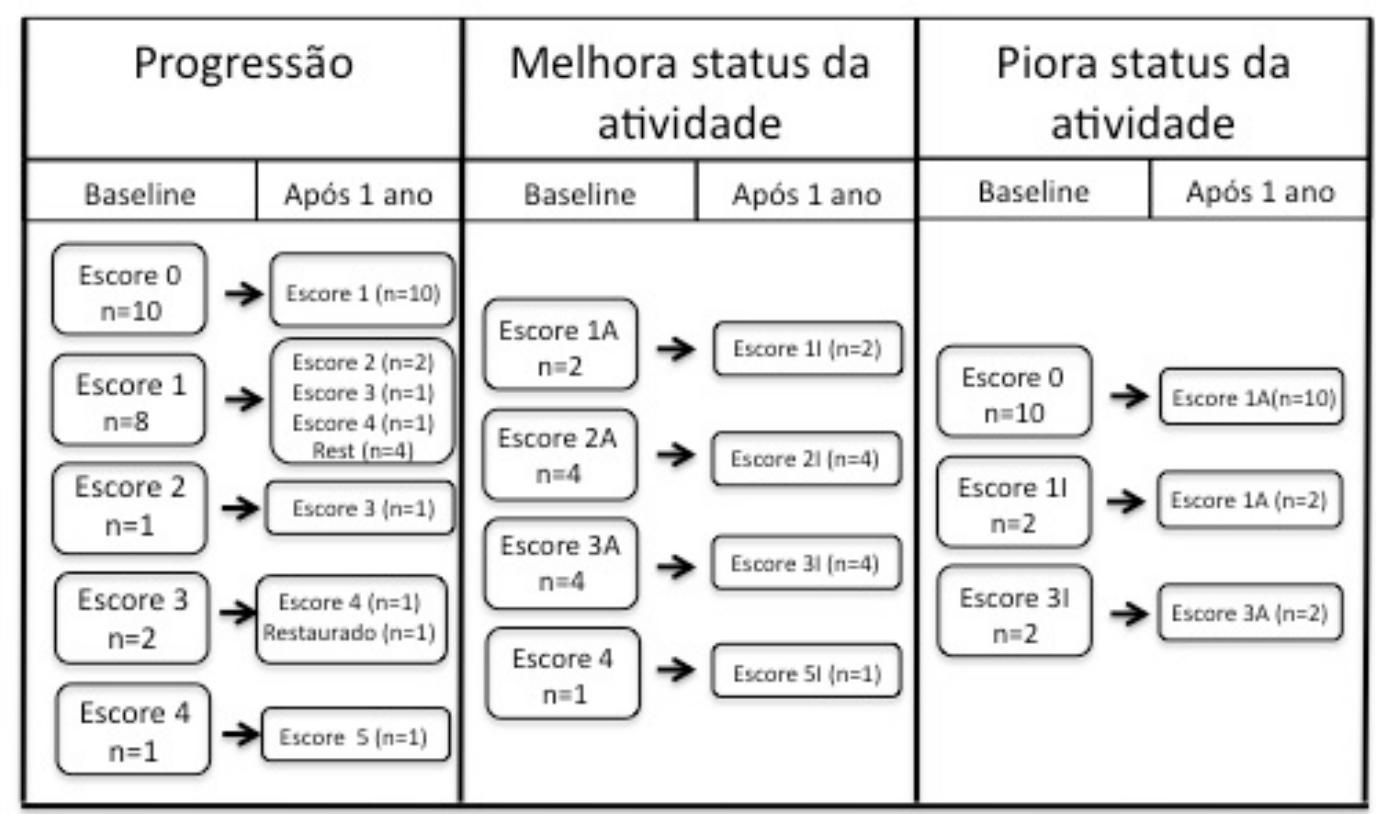

Figura 5.1 - Diagrama da evolução das lesões de cárie verificada pela validação preditiva realizada após 1 ano 
Considerando o desfecho melhora da condição de atividade da superfície, observou-se que 24 superfícies (13\%) apresentaram tal ocorrência, sendo a maioria delas (79\%) lesões em esmalte (escore 1 e 2 ), que se inativaram (Figura 5.1). As medidas de fluorescência a laser também não foram associadas a maior risco de haver melhora no status de atividade das lesões de cárie (Tabelas 5.6 e 5.7). Isso foi válido para ambos os tempos de secagem.

Pouco mais de $10 \%$ da amostra da validação concorrente apresentou piora da condição inicial após um ano. Embora, os valores médios sugerissem medidas maiores para os dentes em que não houve piora da condição de atividade, esse parâmetro não foi associado às leituras de fluorescência a laser (Tabelas 5.6 e 5.7). Cerca de $70 \%$ dos casos de piora da condição de atividade foram superfícies inicialmente classificadas como hígidas que se passaram a apresentar lesões iniciais ativas (Figura 5.1).

Maiores valores de DIF 30s-3s também não foram associados a maior risco de progressão ou de mudança de status de atividade nas superfícies oclusais de dentes decíduos.

Tabela 5.6 - Médias \pm desvios-padrões das leituras obtidas com o aparelho de fluorescência a laser (Ddpen) considerando a evolução das lesões de acordo com a validação preditiva ( $\mathrm{n}=19$ pacientes, 106 superfícies oclusais)

\begin{tabular}{ccccccc}
\hline & \multicolumn{2}{c}{ PROGRESSÃO } & $\begin{array}{c}\text { MELHORA STATUS DE } \\
\text { ATIVIDADE }\end{array}$ & \multicolumn{2}{c}{$\begin{array}{c}\text { PIORA DO STATUS DE } \\
\text { ATIVIDADE }\end{array}$} \\
& NÃO & SIM & NÃO & SIM & NÃO & SIM \\
\hline DDpen 3s & $18,4 \pm 24,6$ & $18,5 \pm 23,4$ & $18,9 \pm 25,9$ & $16,8 \pm 17,2$ & $19,6 \pm 24,8$ & $10,8 \pm 18,1$ \\
DDpen 30s & $19,9 \pm 26,3$ & $19,4 \pm 25,2$ & $20,4 \pm 28,0$ & $17,6 \pm 17,4$ & $21,3 \pm 27,0$ & $9,7 \pm 14,6$ \\
\hdashline DIF 30s-3S** & $1,41 \pm 6,5$ & $-0,97 \pm 4,4$ & $1,5 \pm 7,3$ & $0,8 \pm 4,6$ & $1,7 \pm 7,0$ & $-1,0 \pm 4,8$ \\
\hline
\end{tabular}


Tabela 5.7 - Análise de regressão logística multinível da associação entre a fluorescência a laser (DDpen) e a evolução das lesões de acordo com a validação preditiva ( $n=19$ pacientes, 106 superfícies oclusais)

\begin{tabular}{|c|c|c|c|c|c|}
\hline \multirow{2}{*}{ Desfecho/Variáveis } & & & & & \\
\hline & COEF & EP & RR & $95 \%$ IC & $\mathbf{p}^{*}$ \\
\hline \multicolumn{6}{|l|}{ Progressão } \\
\hline $3 s$ & $-0,004$ & $\mathbb{0}, \mathbb{1 1 1 0}$ & $1,0,00$ & 0,98 a 1,02 & 0,67 \\
\hline $30 \mathrm{~s}$ & $-0,009$ & $0, \mathbb{0}, \mathbf{0 1 1}$ & $0, \$, 99$ & 0,97 a 1,01 & 0,42 \\
\hline DIF 30s-3s & $-0,059$ & $0,(0, B) 32$ & $0,9,94$ & 0,89 a 1,00 & 0,07 \\
\hline \multicolumn{6}{|c|}{ Melhora do status de atividade } \\
\hline $3 s$ & $-0,006$ & (1,„110 & $1,0,09$ & 0,97 a 1,01 & 0,56 \\
\hline $30 \mathrm{~s}$ & $-0,006$ & $0,0,009$ & $0,9,99$ & 0,98 a 1,01 & 0,51 \\
\hline DIF 30s-3s & $-0,013$ & $0,(0, B) 33$ & $0,9,99$ & 0,93 a 1,05 & 0,70 \\
\hline \multicolumn{6}{|c|}{ Melhora do status de atividade } \\
\hline $3 s$ & $-0,015$ & 0,015 & 0,99 & 0,96 a 1,01 & 0,33 \\
\hline $30 \mathrm{~s}$ & $-0,02$ & 0,017 & 0,98 & 0,95 a 1,01 & 0,23 \\
\hline DIF 30s-3s & $-0,046$ & 0,039 & 0,96 & 0,88 a 1,03 & 0,24 \\
\hline \multicolumn{6}{|c|}{ COEF = Coeficiente de regressão; EP = erro padrão RR: Risco Relativo } \\
\hline \multicolumn{6}{|c|}{ * Valor de $p$ das categorias calculados pelo teste de Wald } \\
\hline
\end{tabular}




\section{DISCUSSÃO}

A atividade de cárie é um forte indicador do prognóstico e velocidade de progressão da doença, sendo mandatória nas tomadas de decisão de tratamento (4). Entretanto, a maioria dos estudos tem despendido maior atenção à questão da profundidade das lesões de cárie, do que propriamente à atividade e às implicações do seu correto diagnóstico para as condutas de tratamento propriamente ditas (28). Um método objetivo poderia ser útil para facilitar a detecção e o monitoramento da atividade das lesões de cárie e diminuir, assim, a subjetividade inerente ao exame de inspeção visual (14).

Nesse contexto, um primeiro estudo do nosso grupo propôs-se a verificar se o método de fluorescência a laser era capaz de diferenciar lesões ativas e inativas, utilizando diferentes tempos de secagem, e validando os resultados obtidos através das leituras do aparelho de fluorescência a laser com validação concorrente (30), como os estudos anteriormente citados (15, 16). Para uma parte da amostra, foi realizada a validação de critério (histológica). Os resultados encontrados foram promissores, demonstrando que o método podia diferenciar lesões cavitadas ativas de inativas e, ainda, a utilização diferença das medidas obtidas após dois tempos diferentes secagem do dente, 3 e 15 segundos, se mostrava como uma alternativa viável para detectar a atividade das lesões de cárie não cavitadas, porém um maior tempo de secagem poderia ser utilizado para verificar se essa diferenciação ocorreria, em lesões não cavitadas, apenas com uma única leitura do aparelho após uma secagem mais prolongada do dente (14).

Além disso, o acompanhamento das crianças avaliadas com o método de fluorescência a laser e a observação sobre a evolução das lesões permitiria, por sua vez, a comprovação ou rejeição da hipótese de que maiores leituras do método de fluorescência a laser poderiam estar associadas a progressão das lesões de cárie. Essa seria, então, a forma mais aceita de validação de métodos que diagnostiquem atividade das lesões 
de cárie $(5,28)$ e poderia ser usada em paralelo com a validação concorrente como forma de confrontar possíveis resultados encontrados.

Baseados no exposto, este estudo foi realizado para testar a hipótese de que se utilizando o aparelho de fluorescência a laser com uma secagem prolongada do dente, este aparelho poderia diferenciar lesões ativas de lesões inativas em esmalte e em dentina, cavitadas e não cavitadas. Entretanto, o aparelho foi capaz de diferenciar somente a atividade das lesões cavitadas, isto é, lesões classificadas como escore 3 ou escores superiores. Para lesões não cavitadas, a fluorescência a laser, assim como no estudo anterior (14), continuou não permitindo a diferenciação pelas medidas isoladas. Quando divididas pela profundidade clínica, ao invés de pela integridade superficial, efeito semelhante foi observado, já que as lesões sem evidência clínica de comprometimento dentinário também não puderam ser diferenciadas pelo método.

Uma possível explicação para os resultados encontrados neste estudo, em relação à leitura das lesões iniciais consideradas inativas, é o fato que a fossas e fissuras pigmentadas apresentaram maiores valores na leitura do aparelho de fluorescência a laser. Isso pode ocorrer, mesmo que essas lesões não tenham menor contaminação comparadas às lesões cavitadas (94) devido ao maior acúmulo de porfirinas nesse tipo de lesão (62). Sendo assim, a pigmentação das fossas e fissuras em lesões iniciais de cárie pode influenciar negativamente no uso desse método na avaliação da atividade das lesões iniciais, o que mascararia o efeito da atividade da lesão na variação da fluorescência medida. Entretanto, mesmo quando a análise foi ajustada por esse parâmetro, a fluorescência das lesões inativas foi semelhante à das lesões ativas, não permitindo, portanto, a distinção do status das lesões iniciais pelo método da fluorescência a laser. Outros estudos realizados com lesões iniciais $(15,16,93)$ podem ter encontrado diferenças entre lesões com diferentes status de atividade em função do tipo de superfície, já que a maioria deles foi realizado em superfícies lisas.

Além de não permitir a distinção das lesões quanto ao seu status de atividade, a secagem demasiada no tempo de secagem do dente, 
estendendo até 30s parece prejudicar o método em algumas de suas propriedades. Em estudo prévio, apesar de as lesões não cavitadas não poderem ser distinguidas pela medição mais prolongada, utilizando-se a diferença entre essas medidas $e$ as medidas feitas com a secagem convencional (3s), conseguia-se distinguir as lesões não cavitadas de acordo com a atividade. Isso, entretanto, deixa de ocorrer quando a secagem de 30 s é empregada nessa fórmula de diferenças entre as leituras (DIF 30s-3s). Mesmo sabendo que aumento nos valores de fluorescência a laser pode ocorrer após desidratação, graças a uma maior concentração de substância orgânica na lesão de cárie causada pela perda de água (81), essa secagem muito prolongada pode ter alterado o espalhamento do laser $\mathrm{e}$ da fluorescência emitida pelos tecidos dentários (95), confundindo o aparelho em relação à detecção das lesões e sua atividade, superpondo, assim, o efeito esperado que as lesões ativas, por serem mais infectadas, apresentariam maiores leituras.

A não diferenciação das lesões não cavitadas ou em esmalte pelo uso prolongado da secagem em associação com o método de fluorescência a laser também foi corroborado pela validação preditiva. Apesar de, para essa validação, dispormos de uma amostra de um tamanho menor, os resultados dessa etapa vão de encontro aos até então discutidos. A grande maioria dos dentes acompanhados após um ano, representavam inicialmente lesões iniciais, principalmente classificadas por escores 1 e 2 do ICDAS, e as medidas de fluorescência a laser não foram associadas a maior risco de progressão dessas lesões, nem de alterações de status ao longo do tempo decorrido.

Por outro lado, poucas lesões progrediram independentemente da sua condição de atividade. Uma das explicações para esse resultado pode ser o fato que as crianças que participaram deste estudo foram inseridas em programas preventivos e, portanto, estão realizando o controle dos fatores etiológicos ligados à cárie e, assim, estão tendo a velocidade de progressão destas lesões ainda mais diminuída e não mostrando progressão evidente ao longo de um ano. Antevendo essa possibilidade, foram também incluídos 
desfechos substitutos para verificar possível associação entre evolução das lesões e as leituras do aparelho de fluorescência a laser. No entanto, também para esses desfechos não foi notada associação com as medidas de fluorescência a laser.

As lesões cavitadas, por sua vez, já puderam ser diferenciadas em ativas e inativas mesmo após o tempo de secagem convencional de 3s, corroborando achados prévios (14). Lesões microcavitadas em esmalte apresentam nível moderado de infecção na junção amelodentinária $(94,96)$, ocasionando um número maior de metabólitos bacterianos e, consequentemente, um aumento nas leituras do DDpen (14).

Quando consideramos a validação concorrente, temos que considerar que muitas lesões microcavitadas (escore 3 ) em dentes decíduos estão histologicamente em dentina $(21,22,69)$. Assim, poder-se-ia inferir que o método de fluorescência seria válido, por consequência, para diferenciação de lesões em dentina, mesmo aquelas que visualmente não aparentam comprometimento dentinário, ou seja, lesões mais na porção mais externa da dentina.

Vale ressaltar que distinguir uma lesão ativa de uma inativa em uma cavidade ampla envolvendo dentina não é uma tarefa difícil, até porque lesões inativas em dentina estão associadas a grandes destruições que se tornaram inativas graças à sua conformação, que permitia que o biofilme fosse removido de seu interior (97). Superfícies classificadas como escore 3 , no entanto, por não apresentarem dentina aparente, demandam avaliação do esmalte para classificação da atividade, o que pode levar a uma variabilidade maior entre os examinadores, especialmente em função da rugosidade (dados não publicados), que é um parâmetro bastante influenciado pelo examinador (98). Sendo assim, o método de fluorescência a laser poderia ser útil nos casos que temos lesões microcavitadas, aparentemente em esmalte, lesões essas com as quais encontramos maiores dificuldades em determinar de atividade cárie. No entanto, estudos prospectivos devem ser conduzidos no sentido de testar pontos de corte, checar a viabilidade desse método como uma ferramenta para avaliar atividade das lesões, bem como traçar um 
comparativo com o método visual, que é o método consagrado para tal finalidade.

Como a seleção das crianças foi realizada em indivíduos que procuraram o serviço de triagem, geralmente requerendo intervenção preventiva ou restauradora, os resultados do presente estudo podem ser extrapolados para a população que procura atendimento nos consultórios odontológicos (99). Devemos salientar também que com o uso rotineiro do flúor (100), a doença cárie tem apresentado baixas taxas de progressão em algumas populações. Isso repercute na tendência de se encontrar lesões em fases mais iniciais, ao invés de lesões cavitadas evidentes, principalmente, as que envolvem dentina (101), oferecendo maior oportunidade para controle das mesmas. Entretanto, suscita outro aspecto, que é o da detecção dessas lesões, ou seja, lesões em esmalte com ou sem descontinuidade que, certamente, demandam maiores esforços que a detecção de cavidades evidentes de cárie em dentina e merecem, portanto, maior atenção, pois permitem que medidas de controle sejam instauradas e as necessidades de intervenções futuras de maior complexidade sejam minimizadas.

Certamente, a não necessidade da secagem prolongada para diferenciar lesões cavitadas ativas e inativas seria uma grande contribuição para o custo-benefício do método. Considerando oito superfícies oclusais de molares decíduos examinadas, a secagem adicional poderia, no mínimo, dobrar o tempo para se repetir o exame, acrescido de mais 2 a 4 minutos por criança se usada a secagem de 15 s ou 30 s, respectivamente. Supondo um tempo de 10 minutos para o exame desses dentes com o aparelho e levando em conta o valor médio da hora de trabalho dos profissionais em diferentes partes do Brasil (de $\mathrm{R} \$ 57,47$ a $\mathrm{R} \$ 102,09 /$ hora, segundo dados do Ministério do Trabalho), esse tempo extra dispendido representaria um custo-adicional desnecessário de 10 a 25 reais a ser repassado para o paciente ou a ser arcado pelo próprio profissional. Em se tratando das lesões não cavitadas, cuja evidência disponível é de que a diferença entre as leituras de $15 \mathrm{~s}$ e $3 \mathrm{~s}$ poderiam distinguir o status das lesões, ou ainda, para distinção de lesões cavitadas apenas com a leitura isolada do aparelho de fluorescência a laser, 
a relação de custo-benefício merece ser também testada antes da implementação e da difusão dessas metodologias como rotina na prática clínica. Além disso, o procedimento mais curto é também o mais simples, sendo além de menos oneroso, mais viável de se aplicar clinicamente, além de ser mais confortável ao próprio paciente. 


\section{CONCLUSÕES}

Pode-se concluir que, para superfícies oclusais de dentes decíduos, utilizar a secagem prolongada por 30 s não traz benefícios adicionais na avaliação da atividade de lesões de cárie, uma vez que:

1) O método baseado na fluorescência a laser é capaz de diferenciar lesões de cárie cavitadas ativas e inativas independente do tempo de secagem do dente, sendo a opção de secagem por 3s mais simples e menos onerosa;

2) A medida da diferença entre as leituras obtidas após secagem de $3 \mathrm{~s}$ e 30s não auxilia na classificação do status de atividade das lesões de cárie não cavitadas. 


\section{REFERÊNCIAS ${ }^{1}$}

1. Angmar-Mansson BE, al-Khateeb S, Tranaeus S. Caries Diagnosis. J Dent Educ. 1998 Oct;62(10):771-80.

2. Pitts NB. Modern concepts of caries measurement. J Dent Res. 2004;83 Spec No C:C43-7.

3. Nyvad B, Fejerskov O. Assessing the stage of caries lesion activity on the basis of clinical and microbiological examination. Community Dent Oral Epidemiol. 1997 Feb;25(1):69-75.

4. Nyvad B. Diagnosis versus detection of caries. Caries Res. 2004;38(3):192-8.

5. Baelum V. What is an appropriate caries diagnosis? Acta Odontol Scand. 2010 Mar;68(2):65-79.

6. $\quad$ Pitts N. "ICDAS"--an international system for caries detection and assessment being developed to facilitate caries epidemiology, research and appropriate clinical management. Community Dent Health 2004 Sep;21(3):193-8.

7. Baelum V, Machiulskiene V, Nyvad B, Richards A, Vaeth M. Application of survival analysis to carious lesion transitions in intervention trials. Community Dent Oral Epidemiol. 2003 Aug;31(4):252-60.

8. Ekstrand KR, Ricketts DNJ, Kidd EAM, Qvist V, Schou S. Detection, diagnosing, monitoring and logical treatment of occlusal caries in relation to lesion activity and severity: an in vivo examination with histological validation. Caries Res. 1998;32(4):247-54.

9. Nyvad B, Machiulskiene V, Baelum V. Reliability of a new caries diagnostic system differentiating between active and inactive caries lesions. Caries Res. 1999 Jul-Aug;33(4):252-60.

${ }^{1}$ De acordo com o Estilo Vancouver 
10. Bader JD, Shugars DA, Bonito AJ. A systematic review of the performance of methods for identifying carious lesions. J Public Health Dent. 2002 Fall;62(4):201-13.

11. Mendes FM, Pinheiro SL, Bengtson AL. Effect of alteration in organic material of the occlusal caries on DIAGNOdent readings. Braz Oral Res. 2004 Apr-Jun;18(2):141-4.

12. Hibst R, Paulus R, Lussi A. Detection of occlusal caries by laser fluorescence: Basic and Clinical investigations. Med Laser Appl. 2001;16:20513.

13. Buchalla W. Comparative fluorescence spectroscopy shows differences in noncavitated enamel lesions. Caries Res. 2005 MarApr;39(2):150-6.

14. Braga MM, de Benedetto MS, Imparato JC, Mendes FM. New methodology to assess activity status of occlusal caries in primary teeth using laser fluorescence device. J Biomed Opt. 2010 Jul-Aug;15(4):047005.

15. Pinelli C, Campos Serra M, de Castro Monteiro Loffredo L. Validity and reproducibility of a laser fluorescence system for detecting the activity of white-spot lesions on free smooth surfaces in vivo. Caries Res. 2002 JanFeb;36(1):19-24.

16. Andersson A, Sköld-Larsson K, Hallgren A, Petersson LG, Twetman S. Measurement of enamel lesion regression with a laser fluorescence device (DIAGNOdent): a pilot study. Orthod. 2004;1(3):201-5.

17. Braga MM, Mendes FM, Ekstrand KR. Detection Activity Assessment and Diagnosis of Dental Caries Lesions. Dent Clin North Am. 2010 Jul;54(3):479-93.

18. Ismail Al, Sohn W, Tellez M, Amaya A, Sen A, Hasson H, et al. The International Caries Detection and Assessment System (ICDAS): an integrated system for measuring dental caries. Community Dent Oral Epidemiol. 2007 Jun;35(3):170-8. 
19. Ekstrand KR, Martignon S, Ricketts DJ, Qvist V. Detection and activity assessment of primary coronal caries lesions: a methodologic study. Oper Dent. 2007 May-Jun;32(3):225-35.

20. Committee. ICDaASIC. International Caries Detection and Assessment System (ICDAS II) : Criteria Manual. In: Committee. ICDaASIC, editor. Workshop held in Baltimore, Maryland, March 12th-14th 2005; Baltimore, Maryland2005.

21. Braga MM, Mendes FM, Martignon S, Ricketts DN, Ekstrand KR. In vitro comparison of Nyvad's system and ICDAS-II with Lesion Activity Assessment for evaluation of severity and activity of occlusal caries lesions in primary teeth. Caries Res. 2009;43(5):405-12.

22. Braga MM, Ekstrand KR, Martignon S, Imparato JC, Ricketts DN, Mendes FM. Clinical Performance of Two Visual Scoring Systems in Detecting and Assessing Activity Status of Occlusal Caries in Primary Teeth. Caries Res. 2010 Jun 8;44(3):300-8.

23. Verdonschot $\mathrm{EH}$, van der Veen $\mathrm{MH}$. [Lasers in dentistry 2. Diagnosis of dental caries with lasers]. Ned Tijdschr Tandheelkd. 2002 Apr;109(4):122-6.

24. Ando M, Stookey GK, Zero DT. Ability of quantitative light-induced fluorescence (QLF) to assess the activity of white spot lesions during dehydration. Am J Dent. 2006 Feb;19(1):15-8.

25. Hintze H, Wenzel A. Diagnostic outcome of methods frequently used for caries validation. A comparison of clinical examination, radiography and histology following hemisectioning and serial tooth sectioning. Caries Res. 2003 Mar-Apr;37(2):115-24.

26. Huysmans MCDNJM, Longbottom $C$. The challenges of validating diagnostic methods and selecting appropriate gold standards. J Dent Res. 2004;83(Spec No C):C48-52.

27. Norman GR, Streiner DL. Basic concepts. In: Norman GR, Streiner DL, editors. Biostatistics: the bare essentials. 1. 2nd ed. Hamilton: B.C. Decker; 2000. p. 4-14. 
28. Baelum V, Heidmann J, Nyvad B. Dental caries paradigms in diagnosis and diagnostic research. Eur J Oral Sci. 2006 Aug;114(4):263-77.

29. Nyvad B, Machiulskiene V, Baelum V. Construct and predictive validity of clinical caries diagnostic criteria assessing lesion activity. J Dent Res. 2003 Feb;82(2):117-22.

30. Downer MC. Concurrent validity of an epidemiological diagnostic system for caries with the histological appearance of extracted teeth as validating criterion. Caries Res. 1975;9(3):231-46.

31. Gardner IA, Greiner M. Advanced Methods for Test Validation and Interpretation in Veterinary Medicine 1st. ed. Berlin: Frei Universität Berlin; 2002. 89 .

32. MacGregor AB. The extent and distribution of acid in carious dentine. Proc R Soc Med. 1962 December, 1962;55:23-6.

33. Hiraishi N, Kitasako Y, Nikaido T, Foxton RM, Tagami J, Nomura S. Evaluation of active and arrested carious dentin using a pH-imaging microscope and an X-ray analytical microscope. Oper Dent. 2003 SepOct;28(5):598-604.

34. Murakami K, Kitasako Y, Burrow MF, Tagami J. In vitro pH analysis of active and arrested dentinal caries in extracted human teeth using a micro $\mathrm{pH}$ sensor. Dent Mater J. 2006 Sep;25(3):423-9.

35. Dowker SE, Elliott JC, Davis GR, Wilson RM, Cloetens P. Synchrotron $\mathrm{x}$-ray microtomographic investigation of mineral concentrations at micrometre scale in sound and carious enamel. Caries Res. 2004 Nov-Dec;38(6):514-22.

36. Orellana MF, Nelson AE, Carey JP, Heo G, Boychuk DG, Major PW. Surface analysis of etched molar enamel by gas adsorption. J Dent Res. 2008 Jun;87(6):532-6.

37. Ardu S, Feilzer AJ, Devigus A, Krejci I. Quantitative clinical evaluation of esthetic properties of incisors. Dent Mater. 2008 Mar;24(3):333-40. 
38. Yu B, Ahn JS, Lee YK. Measurement of translucency of tooth enamel and dentin. Acta Odontol Scand. 2009 Feb;67(1):57-64.

39. Ando M, Hall AF, Eckert GJ, Schemehorn BR, Analoui M, Stookey GK. Relative ability of laser fluorescence techniques to quantitate early mineral loss in vitro. Caries Res. 1997;31(2):125-31.

40. Elton V, Cooper L, Higham SM, Pender N. Validation of enamel erosion in vitro. J Dent. 2009 May;37(5):336-41.

41. Martin JM, de Almeida JB, Rosa EA, Soares P, Torno V, Rached RN, et al. Effect of fluoride therapies on the surface roughness of human enamel exposed to bleaching agents. Quintessence Int. 2010 Jan-Feb;41(1):71-8.

42. Wong FS, Anderson P, Fan H, Davis GR. X-ray microtomographic study of mineral concentration distribution in deciduous enamel. Arch Oral Biol. 2004 Nov;49(11):937-44.

43. Gao XJ, Fan Y, Kent RL, Jr., Van Houte J, Margolis HC. Association of caries activity with the composition of dental plaque fluid. J Dent Res. 2001 Sep;80(9):1834-9.

44. Pretty IA, Edgar WM, Higham SM. A study to assess the efficacy of a new detergent free, whitening dentifrice in vivo using QLF planimetric analysis. Br Dent J. 2004 Nov 13;197(9):561-6; discussion 551.

45. Alfano RR, Yao SS. Human teeth with and without dental caries studied by visible luminescent spectroscopy. J Dent Res. 1981 Feb;60(2):1202.

46. Foreman PC. The excitation and emission spectra of fluorescent components of human dentine. Arch Oral Biol. 1980;25(10):641-7.

47. Sundstrom F, Fredriksson K, Montan S, Hafstrom-Bjorkman U, Strom J. Laser-induced fluorescence from sound and carious tooth substance: spectroscopic studies. Swed Oral Biol. 1985;9(2):71-80.

48. Hibst R, Gall R. Development of a diode laser-based fluorescence caries detector. Caries Res. 1998;32(4):294. 
49. Mendes FM, Nicolau J, Duarte DA. Evaluation of the Effectiveness of Laser Fluorescence in Monitoring in vitro Remineralization of Incipient Caries Lesions in Primary Teeth. Caries Res. 2003 Nov-Dec;37(6):442-4.

50. Mendes FM, Pinheiro SL, Bengtson AL. Effect of alteration in organic material of the occlusal caries on DIAGNOdent readings. Pesqui Odontol Bras. 2004 Apr-Jun;18(2):141-4.

51. Braun A, Krause F, Jepsen S. The influence of the calibration mode of a laser fluorescence device on caries detection. Caries Res. 2005 MarApr;39(2):144-9.

52. Braga MM, Mendes FM, Martins CR, Imparato JC. Effect of the calibration method of a laser fluorescence device for detecting occlusal caries in primary molars. Pediatr Dent. 2006 Sep-Oct;28(5):451-4.

53. Alwas-Danowska HM, Plasschaert AJM, Suliborski S, Verdonschot EH. Reliability and validity issues of laser fluorescence measurements in occlusal caries diagnosis. J Dent. 2002 May;30(4):129-34.

54. Anttonen V, Seppa L, Hausen H. Clinical study of the use of the laser fluorescence device DIAGNOdent for detection of occlusal caries in children. Caries Res. 2003 Jan-Feb;37(1):17-23.

55. Anttonen V, Seppa L, Hausen H. A follow-up study of the use of DIAGNOdent for monitoring fissure caries in children. Community Dent Oral Epidemiol. 2004 Aug;32(4):312-8.

56. Astvaldsdottir A, Holbrook WP, Tranaeus S. Consistency of DIAGNOdent instruments for clinical assessment of fissure caries. Acta Odontol Scand. 2004 Aug;62(4):193-8.

57. Attrill DC, Ashley PF. Occlusal caries detection in primary teeth: a comparison of DIAGNOdent with conventional methods. Br Dent J. $2001 \mathrm{Apr}$ 28;190(8):440-3.

58. Baseren NM, Gokalp S. Validity of a laser fluorescence system (DIAGNOdent) for detection of occlusal caries in third molars: an in vitro study. J Oral Rehabil. 2003 Dec;30(12):1190-4. 
59. Costa AM, Yamaguti PM, De Paula LM, Bezerra ACB. In vitro study of laser diode $655 \mathrm{~nm}$ diagnosis of occlusal caries. ASDC J Dent Child. 2002 Sep-Dec;69(3):249-53, 33.

60. El-Housseiny AA, Jamjoum H. Evaluation of visual, explorer, and a laser device for detection of early occlusal caries. J Clin Pediatr Dent. 2001 Fall;26(1):41-8.

61. Ferreira Zandoná AG, Analoui M, Beiswanger BB, Isaacs RL, Kafrawy $A H$, Eckert GJ, et al. An in vitro comparison between laser fluorescence and visual examination for detection of demineralization in occlusal pits and fissures. Caries Res. 1998;32(3):210-8.

62. Francescut $P$, Lussi A. Correlation between fissure discoloration, Diagnodent measurements, and caries depth: an in vitro study. Pediatr Dent. 2003 Nov-Dec;25(6):559-64.

63. Fung L, Smales R, Ngo H, Moun G. Diagnostic comparison of three groups of examiners using visual and laser fluorescence methods to detect occlusal caries in vitro. Aust Dent J. 2004 Jun;49(2):67-71.

64. Heinrich-Weltzien R, Kuhnisch J, Oehme T, Ziehe A, Stosser L, GarciaGodoy F. Comparison of different DIAGNOdent cut-off limits for in vivo detection of occlusal caries. Oper Dent. 2003 Nov-Dec;28(6):672-80.

65. Kuhnisch J, Ziehe A, Brandstadt A, Heinrich-Weltzien R. An in vitro study of the reliability of DIAGNOdent measurements. J Oral Rehabil. 2004 Sep;31(9):895-9.

66. Lussi A, Francescut P. Performance of conventional and new methods for the detection of occlusal caries in deciduous teeth. Caries Res. 2003 JanFeb;37(1):2-7.

67. Lussi A, Imwinkelried S, Pitts NB, Longbottom C, Reich E. Performance and reproducibility of a laser fluorescence system for detection of occlusal caries in vitro. Caries Res. 1999 Jul-Aug;33(4):261-6.

68. Lussi A, Megert B, Longbottom C, Reich E, Francescut P. Clinical performance of a laser fluorescence device for detection of occlusal caries lesions. Eur J Oral Sci. 2001 Feb;109(1):14-9. 
69. Rocha RO, Ardenghi TM, Oliveira LB, Rodrigues CRMD, Ciamponi AL. In vivo Effectiveness of Laser Fluorescence Compared to Visual Inspection and Radiography for the Detection of Occlusal Caries in Primary Teeth. Caries Res. 2003 Nov-Dec;37(6):437-41.

70. Sheehy EC, Brailsford SR, Kidd EAM, Beighton D, Zoitopoulos L. Comparison between visual examination and a laser fluorescence system for in vivo diagnosis of occlusal caries. Caries Res. 2001 Nov-Dec;35(6):421-6.

71. Shi $X Q$, Welander $U$, Angmar-Mansson B. Occlusal caries detection with KaVo DIAGNOdent and radiography: an in vitro comparison. Caries Res. 2000 Mar-Apr;34(2):151-8.

72. Bengtson AL, Gomes AC, Mendes FM, Cichello LRD, Bengtson NG, Pinheiro SL. Influence of examiner's clinical experience in detecting occlusal caries lesions in primary teeth. Pediatr Dent. 2005 May-Jun;27(3):238-43.

73. Ouellet A, Hondrum SO, Pietz DM. Detection of occlusal carious lesions. Gen Dent. 2002 Jul-Aug;50(4):346-50.

74. Heinrich-Weltzien R, Weerheijm KL, Kuhnisch J, Oehme T, Stosser L. Clinical evaluation of visual, radiographic, and laser fluorescence methods for detection of occlusal caries. ASDC J Dent Child. 2002 May-Aug;69(2):127-32, 3.

75. Cortes DF, Ellwood RP, Ekstrand KR. An in vitro comparison of a combined FOTI/visual examination of occlusal caries with other caries diagnostic methods and the effect of stain on their diagnostic performance. Caries Res. 2003 Jan-Feb;37(1):8-16.

76. Pereira AC, Verdonschot EH, Huysmans MCDNJM. Caries detection methods: can they aid decision making for invasive sealant treatment? Caries Res. 2001 Mar-Apr;35(2):83-9.

77. Braga MM, Mendes FM, Imparato JCP, Rodrigues CRMD. Effect of cut-off points on performance of laser fluorescence for detecting occlusal caries. J Clin Pediatr Dent. 2007;31(4). 
78. Braga MM, Nicolau J, Rodrigues CRM, Imparato JCP, Mendes FM. Laser fluorescence device does not perform well in detection of early caries in primary teeth: an in vitro study. Oral Health Prev Dent. 2008;6(2):165-9.

79. Bader JD, Shugars DA. A systematic review of the performance of a laser fluorescence device for detecting caries. J Am Dent Assoc. 2004 Oct;135(10):1413-26.

80. Diniz MB, Rodrigues JD, Paula AB, Cordeiro RD. In vivo evaluation of laser fluorescence performance using different cut-off limits for occlusal caries detection. Lasers Med Sci. 2008 Mar 1.

81. Mendes FM, Hissadomi M, Imparato JCP. Effects of drying time and the presence of plaque on the in vitro performance of laser fluorescence in occlusal caries of primary teeth. Caries Res. 2004 Mar-Apr;38(2):104-8.

82. Cabral RM, Mendes FM, Nicolau J, Zezell DM. The influence of PVC seal wrap and probe tips autoclaving on the in vitro performance of laser fluorescence device in occlusal caries in primary teeth. $\mathrm{J}$ Clin Pediatr Dent. 2006 Summer;30(4):306-9.

83. Rocha-Cabral RM, Mendes FM, Miura F, Ribeiro Ada C, Braga MM, Zezell DM. Autoclaving and battery capacity influence on laser fluorescence measurements. Acta Odontol Scand. 2008 Apr;66(2):122-7.

84. Mendes FM, Ganzerla E, Nunes AF, Puig AVC, Imparato JCP. Use of high-powered magnification to detect occlusal caries in primary teeth. Am J Dent. 2006 Feb;19(1):19-22.

85. Mendes FM, Nicolau J. Utilization of laser fluorescence to monitor caries lesions development in primary teeth. J Dent Child (Chic). 2004 MayAug;71(2):139-42.

86. Mendes FM, Siqueira WL, Mazzitelli JF, Pinheiro SL, Bengtson AL. Performance of DIAGNOdent for detection and quantification of smoothsurface caries in primary teeth. J Dent. 2005 Jan;33(1):79-84.

87. Shi XQ, Tranaeus S, Angmar-Mansson B. Validation of DIAGNOdent for quantification of smooth-surface caries: an in vitro study. Acta Odontol Scand. 2001 Apr;59(2):74-8. 
88. Shi XQ, Tranaeus S, Angmar-Mansson B. Comparison of QLF and DIAGNOdent for quantification of smooth surface caries. Caries Res. 2001 Jan-Feb;35(1):21-6.

89. Mendes FM, de Oliveira E, Araujo de Faria DL, Nicolau J. Ability of laser fluorescence device associated with fluorescent dyes in detecting and quantifying early smooth surface caries lesions. J Biomed Opt. 2006 MarApr;11(2):240-47.

90. Alencar CJ, Braga MM, de Oliveira E, Nicolau J, Mendes FM. Dyeenhanced laser fluorescence detection of caries lesions around brackets. Lasers Med Sci. 2009 Nov;24(6):865-70.

91. Skold-Larsson K, Fornell AC, Lussi A, Twetman S. Effect of topical applications of a chlorhexidine/thymol-containing varnish on fissure caries assessed by laser fluorescence. Acta Odontol Sacnd. 2004 Dec;62(6):339-42.

92. Lussi A, Hibst R, Paulus R. DIAGNOdent: an optical method for caries detection. J Dent Res. 2004;83(Spec No C):C80-C3.

93. Gokalp S, Baseren M. Use of laser fluorescence in monitoring the durability and cariostatic effects of fluoride and chlorhexidine varnishes on occlusal caries: A clinical study. Quintessence Int. 2005 Mar;36(3):183-90.

94. Ricketts DN, Ekstrand KR, Kidd EA, Larsen T. Relating visual and radiographic ranked scoring systems for occlusal caries detection to histological and microbiological evidence. Oper Dent. 2002 MayJun;27(3):231-7.

95. Darling CL, Huynh GD, Fried D. Light scattering properties of natural and artificially demineralized dental enamel at $1310 \mathrm{~nm}$. J Biomed Opt. 2006 May-Jun;11(3):34023.

96. Ekstrand KR. Improving clinical visual detection--potential for caries clinical trials. J Dent Res. 2004;83(Spec No C):C67-71.

97. Mejare I, Stenlund H, Zelezny-Holmlund C. Caries incidence and lesion progression from adolescence to young adulthood: a prospective 15-year cohort study in Sweden. Caries Res. 2004 Mar-Apr;38(2):130-41. 
98. Ando M, Eckert GJ, Zero DT. Preliminary study to establish a relationship between tactile sensation and surface roughness. Caries Res. 2010;44(1):24-8.

99. Novaes TF, Matos R, Braga MM, Imparato JC, Raggio DP, Mendes FM. Performance of a pen-type laser fluorescence device and conventional methods in detecting approximal caries lesions in primary teeth--in vivo study. Caries Res. 2009;43(1):36-42.

100. Spencer AJ, Armfield JM, Slade GD. Exposure to water fluoridation and caries increment. Community Dent Health. 2008 Mar;25(1):12-22.

101. Mejare I, Kallest I C, Stenlund H. Incidence and progression of approximal caries from 11 to 22 years of age in Sweden: A prospective radiographic study. Caries Res. 1999;33(2):93-100. 
APÊNDICE A - Termo de Consentimento Livre e Esclarecido

\section{TERMO DE CONSENTIMENTO LIVRE E ESCLARECIDO}

De acordo com o item IV do Informe Epidemiológico do SUS, Conselho Nacional de Saúde, Resolução 196/1996 “O respeito devido à dignidade humana exige que toda pesquisa se processe após consentimento livre e esclarecido dos sujeitos, indivíduos ou grupos que por si e/ou por seus representantes legais manifestem a sua anuência à participação na pesquisa".

As informações contidas neste documento foram fornecidas pelos pesquisadores responsáveis pela pesquisa, com a finalidade de convidar o responsável pelo menor voluntário da pesquisa a participar da pesquisa. Através desse documento, o responsável autoriza a participação do menor, com pleno conhecimento dos procedimentos a que seu filho(a) será submetido(a) e de que não é obrigatória sua participação, não havendo nenhuma perda caso se recuse a participar.

\section{Título da Pesquisa:}

Desenvolvimento e avaliação de metodologias para estudo da atividade de lesões de cárie em dentes decíduos

\section{Objetivo principal:}

Avaliar alguns métodos de diagnóstico da atividade de cárie em dentes decíduos (dentes de leite), especificamente quanto a detecção da atividade das lesões nas superfícies oclusais ( parte deitada do dente).

Considerando que a detecção da atividade das lesões é decisiva para a escolha do tratamento a ser instituído é importante o desenvolvimento de métodos capazes de diagnosticar a atividade das lesões de cárie nessa região

\section{Procedimento:}

Em uma mesma consulta, será realizado o exame clínico (com espelho bucal e iluminação do refletor), seguido de evidenciação de placa e motivação do paciente. Numa segunda consulta serão realizados exames 
com aparelho de fluorescência a laser (Diagnodent pen). Os dentes que apresentarem lesões de cárie avançadas receberão os tratamentos necessários . Esses procedimentos serão realizados em consultório odontológico.

\section{Benefício:}

Os participantes da pesquisa, bem como seus responsáveis, participarão de atividades de educação em saúde bucal, na qual se tratará a respeito da cárie dentária e doença periodontal; emprego de corretas técnicas utilizadas para a prevenção da cárie dentária (dieta, higienização). Além disso, as crianças serão examinadas e, havendo necessidade de tratamento, serão encaminhadas para tratamento.

\section{Desconforto/Risco/Prejuízos:}

Os exames oferecem desconfortos e riscos mínimos ao paciente. O exame clínico já iria fazer parte da documentação inicial do paciente, para que se pudesse, depois, fazer um plano de tratamento e só será antecipado pelos pesquisadores. A realização da pesquisa não acarretará em nenhum prejuízo ao seu tratamento odontológico da criança.

\section{Informacões adicionais:}

O voluntário tem a garantia de que receberá resposta a qualquer pergunta e esclarecimento de dúvidas sobre os procedimentos, riscos e benefícios relacionados à pesquisa. Os pesquisadores assumem o compromisso de proporcionar informações atualizadas obtidas durante o estudo, ainda que essas possam afetar a vontade do voluntário em continuar participando do trabalho. A não identificação do voluntário na publicação do trabalho será totalmente respeitada.

\section{Retirada do consentimento:}

O responsável pelo voluntário tem a liberdade de retirar seu consentimento a qualquer momento, deixando de participar do estudo, sem que acarrete em prejuízos para o voluntário.

\section{Consentimento pós-informação:}

Eu certifico que, tendo lido as informações prévias e tendo sido suficiente esclarecido pelos pesquisadores abaixo descritos, sobre todos os itens, estou 
plenamente de acordo com a realização da pesquisa, autorizando, inclusive que se execute no

menor , por qual sou responsável, os procedimentos relacionados a esta pesquisa.

São Paulo, de de 20

Nome participante:

\section{Endereço:} Telefone:

Nome responsável: RG:

\section{ASSINATURA DO RESPONSÁVELPELO PACIENTE RESPONSÁVEIS PELA PESQUISA: \\ Ronilza Matos \\ Profa Dra. Mariana Minatel Braga}

Caso haja alguma dúvida sobre a pesquisa favor contatar a pesquisadora Ronilza Matos no telefone (11) 99911-5000. 
FICHA CLÍNICA

\section{IDENTIFICAÇÃO DO PACIENTE:}

Nome:

Endereço:

Telefone:

Idade E-mail:

Responsável:

2. EXAME GERAL DA CAVIDADE BUCAL DO PACIENTE:

1. ODONTOGRAMA:

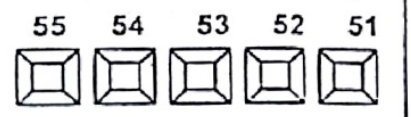

EXAMES ESPE(Z) ICDAS, atividad 四四四四四回

47

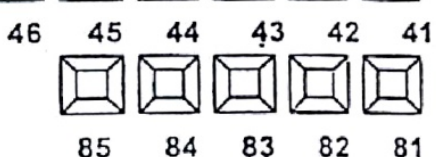

85
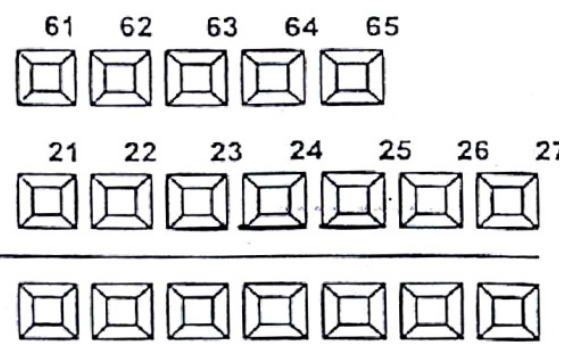

$\begin{array}{lllllll}31 & 32 & 33 & 34 & 35 & 36 & 3:\end{array}$

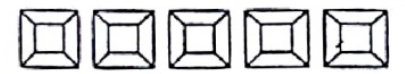

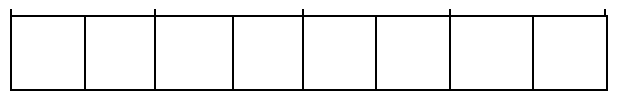
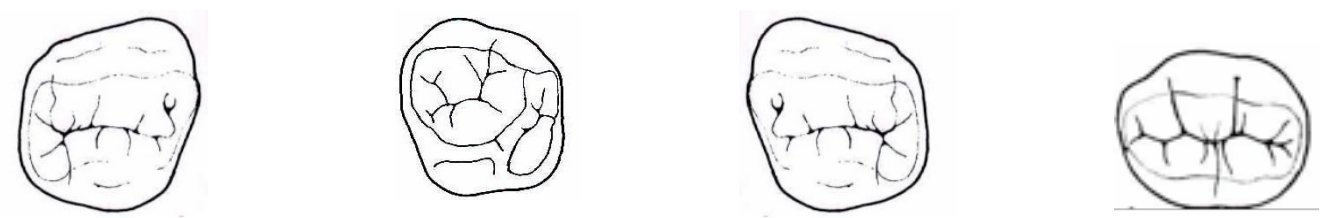


\begin{tabular}{|l|l|l|l|l|l|l|l|}
\hline \multicolumn{2}{|l|}{74} & \multicolumn{2}{|c|}{75} & \multicolumn{2}{|c|}{84} & \multicolumn{2}{c|}{85} \\
& & & & & & & \\
\hline
\end{tabular}
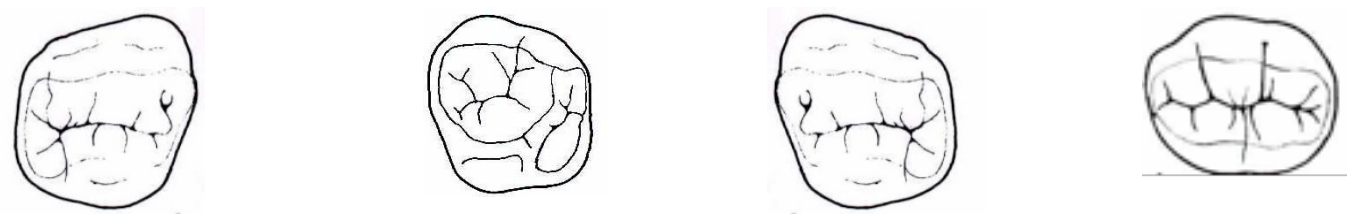

\section{Diagnodent pen}

\begin{tabular}{|c|l|l|l|l|l|l|}
\hline dentes & \multicolumn{2}{|c|}{$\begin{array}{c}\text { Secagem } \\
\text { 3 seg }\end{array}$} & \multicolumn{3}{c|}{$\begin{array}{c}\text { secagem } \\
\text { 30seg }\end{array}$} \\
\hline 54 & & & & & & \\
\hline 55 & & & & & & \\
\hline 64 & & & & & & \\
\hline 65 & & & & & & \\
\hline 74 & & & & & & \\
\hline 75 & & & & & & \\
\hline 84 & & & & & & \\
\hline 85 & & & & & & \\
\hline
\end{tabular}


EXAMES ESPECÍFICOS DA CAVIDADE BUCAL DO PACIENTE

ICDAS II, atividade das lesões e mapeamento - Examinador 2

\begin{tabular}{|c|c|c|c|}
\hline 54 & 55 & 64 & 65 \\
\hline & & & \\
\hline
\end{tabular}
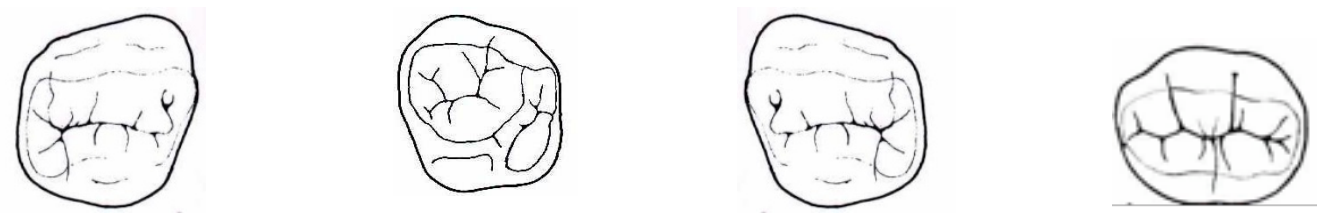

\begin{tabular}{|c|c|c|c|}
\hline 74 & 75 & 84 & 8 \\
\hline & & & \\
\hline
\end{tabular}
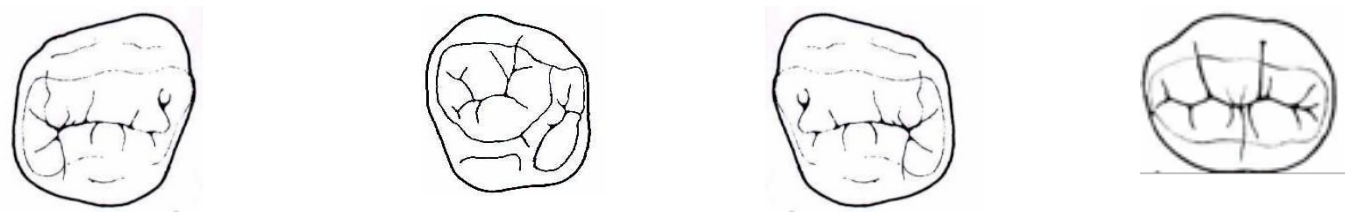
ANEXO A - Parecer do Comitê de Ética e Pesquisa

\author{
UNIVERSIDADE DE SÃO PAULO \\ FACULDADE DE ODONTOLOGIA \\ Comitê de Ética em Pesquisa
}

\author{
PARECER DE APROVAÇĀo \\ FR -304519 \\ Protocolo 181/2009
}

Com base em parecer de relator, o Comitê de Ética em Pesquisa APROVOU o protocolo de pesquisa 'Desenvolvimento e avaliaçăo de metodologias para estudo da atividade de lesóes de cárie em dentes deciduos", de responsabilidade do(a) Pesquisador(a) Ronilza Matos, sob orientaçăo do(a) Prof.(a) Dr.(a) Mariana Minatel Braga.

Tendo em vista a legislaçă vigente, devem ser encaminhados a este Comité relatórios anuais referentes a andamento da pesquisa $\theta$ ao término cópia do trabalho em "cd". Qualquer emenda do projeto original deve ser apresentada a este CEP para apreciaçäo, de forma clara e sucinta, identificando a parte do protocolo a ser modificada e suas justificativas.

Săo Paulo, 11 de março de 2010.

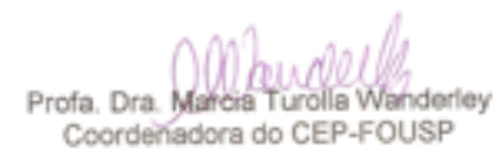

